\title{
Multi-scale snowdrift-permitting modelling of mountain snowpack
}

\author{
Vincent Vionnet ${ }^{1,2}$, Christopher B. Marsh ${ }^{1}$, Brian Menounos ${ }^{3}$, Simon Gascoin ${ }^{4}$, Nicholas E. Wayand ${ }^{1}$, Joseph Shea ${ }^{3}$, \\ Kriti Mukherjee $^{3}$, and John W. Pomeroy ${ }^{1}$ \\ ${ }^{1}$ Centre for Hydrology, University of Saskatchewan, Saskatoon, Canada \\ ${ }^{2}$ Environmental Numerical Prediction Research, Environment and Climate Change Canada, Dorval, QC, Canada \\ ${ }^{3}$ Natural Resources and Environmental Studies Institute and Geography Program, University of Northern \\ British Columbia, Prince George, V2N 4Z9, Canada \\ ${ }^{4}$ Centre d'Études Spatiales de la Biosphère, UPS/CNRS/IRD/INRAE/CNES, Toulouse, France
}

Correspondence: Vincent Vionnet (vincent.vionnet@canada.ca)

Received: 1 July 2020 - Discussion started: 16 July 2020

Revised: 23 October 2020 - Accepted: 21 December 2020 - Published: 17 February 2021

\begin{abstract}
The interaction of mountain terrain with meteorological processes causes substantial temporal and spatial variability in snow accumulation and ablation. Processes impacted by complex terrain include large-scale orographic enhancement of snowfall, small-scale processes such as gravitational and wind-induced transport of snow, and variability in the radiative balance such as through terrain shadowing. In this study, a multi-scale modelling approach is proposed to simulate the temporal and spatial evolution of highmountain snowpacks. The multi-scale approach combines atmospheric data from a numerical weather prediction system at the kilometre scale with process-based downscaling techniques to drive the Canadian Hydrological Model (CHM) at spatial resolutions allowing for explicit snow redistribution modelling. CHM permits a variable spatial resolution by using the efficient terrain representation by unstructured triangular meshes. The model simulates processes such as radiation shadowing and irradiance to slopes, blowing-snow transport (saltation and suspension) and sublimation, avalanching, forest canopy interception and sublimation, and snowpack melt. Short-term, kilometre-scale atmospheric forecasts from Environment and Climate Change Canada's Global Environmental Multiscale Model through its High Resolution Deterministic Prediction System (HRDPS) drive CHM and are downscaled to the unstructured mesh scale. In particular, a new wind-downscaling strategy uses pre-computed wind fields from a mass-conserving wind model at $50 \mathrm{~m}$ resolution to perturb the mesoscale HRDPS wind and to account for the influence of topographic features on wind direction and speed. HRDPS-CHM was applied to simulate snow con-
\end{abstract}

ditions down to $50 \mathrm{~m}$ resolution during winter $2017 / 2018$ in a domain around the Kananaskis Valley $\left(\sim 1000 \mathrm{~km}^{2}\right)$ in the Canadian Rockies. Simulations were evaluated using highresolution airborne light detection and ranging (lidar) snow depth data and snow persistence indexes derived from remotely sensed imagery. Results included model falsifications and showed that both wind-induced and gravitational snow redistribution need to be simulated to capture the snowpack variability and the evolution of snow depth and persistence with elevation across the region. Accumulation of windblown snow on leeward slopes and associated snow cover persistence were underestimated in a CHM simulation driven by wind fields that did not capture lee-side flow recirculation and associated wind speed decreases. A terrain-based metric helped to identify these lee-side areas and improved the wind field and the associated snow redistribution. An overestimation of snow redistribution from windward to leeward slopes and subsequent avalanching was still found. The results of this study highlight the need for further improvements of snowdrift-permitting models for large-scale applications, in particular the representation of subgrid topographic effects on snow transport.

\section{Introduction}

High-mountain snowpacks are characterized by a strong spatial and temporal variability that is associated with elevation, vegetation cover, slope steepness, orientation and wind exposure. This variability results from processes occurring during 
the snow accumulation and ablation periods at a large range of spatial scales (e.g., Pomeroy and Gray, 1995; Pomeroy et al., 1998, 2012, 2016; Clark et al., 2011; Mott et al., 2018). Snow accumulation at the mountain range scale (1$500 \mathrm{~km})$ is primarily dominated by orographic precipitation and results in regions of enhanced or reduced snowfall (e.g., Houze, 2012). At the mountain ridge and slope scales (5 m$1 \mathrm{~km}$ ), preferential deposition of snowfall and blowing-snow transport, including transport in both saltation and suspension layers, strongly impact snow accumulation (e.g., Mott et al. 2018). Redistribution by avalanches (e.g., Bernhardt and Schulz, 2010; Sommer et al., 2015) and surface and blowingsnow sublimation (e.g., MacDonald et al., 2010; Vionnet et al., 2014; Musselman et al., 2015; Sextone et al., 2018) also modify the spatial variability of snow. During the ablation period, spatially varying melt rates result from differences in solar irradiance due to aspect and shading (e.g., Marks and Dozier, 1992; Marsh et al., 2012), in net solar irradiance due to albedo variations (e.g., Dumont et al., 2011; Schirmer and Pomeroy, 2020), in turbulent fluxes (e.g., Winstral and Marks, 2014; Gravelman et al., 2015) and in advected heat from snow-free ground in patchy snow cover conditions (e.g., Mott et al., 2013; Harder et al., 2017; Schlögl et al., 2018).

The multi-scale variability of mountain snow represents a challenge for snow models used in support of avalanche hazard forecasting (Morin et al., 2020), hydrological predictions (e.g., Warscher et al., 2013; Brauchli et al., 2017; Freudiger et al., 2017) and climate projections (e.g., Rasouli et al., 2014; Hanzer et al., 2018) in mountainous terrain. Several modelling strategies have been proposed to face this challenge and to capture this multi-scale variability. At the mountain range scale, atmospheric models at sufficient resolutions (4 km or finer) can provide valuable information on the variability of snowfall and resulting snow accumulation (e.g., Prein et al., 2015; Lundquist et al., 2019; Fang and Pomeroy, 2020). Indeed, at these resolutions, atmospheric models operate at convection-permitting scales and explicitly represent convection and highly resolved vertical motions, achieving improved estimates of snowfall (e.g., Rasmussen et al., 2011). Sub-grid parameterizations of snow depth have been proposed to represent the snow variability at the mountain ridge and slope scale for snowpack models operating at kilometre scales (Liston, 2004; Helbig and van Herwijnen, 2017; He and Ohara, 2019). Another strategy consists of explicitly modelling the snow evolution at the mountain ridge and slope scales at resolutions ranging from a few metres to $200 \mathrm{~m}$ (Liston, 2004; Musselman et al., 2015). At these scales, the variability of snow accumulation can be represented using (i) simple parameterizations to adjust snowfall as a function of topographic parameters (e.g., Winstral and Marks, 2002; Hanzer et al., 2016) or (ii) models that explicitly represent preferential deposition and/or wind-induced snow redistribution (e.g., Essery et al., 1999; Durand et al., 2005; Pomeroy et al., 2007; Liston et al., 2007; Lehning et al., 2008; Sauter et al., 2013; Vionnet et al., 2014; Marsh et al., 2020a). These models can be classified as snowdriftpermitting models since they operate at sufficient resolutions ( $200 \mathrm{~m}$ or finer) to activate the horizontal redistribution of snow between computational elements. High-resolution remote sensing data assimilation can also be used at these scales to correct spatial biases in the atmospheric forcing and to account for missing physical processes in the models (e.g., Durand and Margulis, 2008; Baba et al., 2018).

Snowdrift-permitting models simulate wind-induced snow transport in the saltation and suspension layers (e.g, Pomeroy and Gray, 1995). As proposed by Mott et al. (2018), they can be divided into two main categories: (i) models solving the vertically integrated mass flux in the saltation and suspension layers (Essery et al., 1999; Durand et al., 2005; Pomeroy et al., 2007; Liston et al., 2007) and (ii) models solving the three-dimensional (3-D) advection-turbulent diffusion equation of blown snow particles in the atmosphere (Gauer, 1998; Lehning et al., 2008; Schneiderbauer and Prokop, 2011; Sauter et al., 2013; Vionnet et al., 2014). One of the main challenges for all these models is obtaining accurate driving wind fields at sufficient high resolution since they strongly impact the accuracy of simulated snow redistribution (Mott and Lehning, 2010; Musselman et al., 2015). Models of the first category need two-dimensional (2-D) driving wind fields. Liston et al. (2007), inspired by Ryan (1977), proposed the use of terrain-based parameters to adjust distributed wind fields to the local topography. These distributed wind fields can be obtained from interpolated station data (Gascoin et al., 2013; Sextone et al., 2018), hourly output from regional climate models at a convectivepermitting scale (Reveillet et al., 2020) or a pre-computed wind field library using an atmospheric model (Berhnardt et al., 2010). Essery et al. (1999) used a linearized turbulence model (Walmsley et al., 1982) to build a pre-computed library of 2-D wind maps to distribute wind measurements from station data. Musselman et al. (2015) showed that this approach led to more accurate simulations of snow redistribution around an alpine crest than wind fields derived from the terrain-based parameters proposed by Liston et al. (2007). Models of the second category require a 3-D representation of the wind field and associated atmospheric turbulence. In this case, driving wind fields can be obtained from computational fluid dynamics (CFD) models (Gauer, 1998; Schneiderbauer and Prokop, 2011) or atmospheric models in largeeddy simulation (LES) mode used to generate a library of pre-computed wind fields (Lehning et al., 2008; Mott and Lehning, 2010) or fully coupled to a snowpack model (Vionnet et al., 2014). These advanced models can be used for detailed studies such as the feedbacks between blowing-snow sublimation and the atmosphere (Groot Zwaaftink et al., 2011) or the processes driving the variability of snow accumulation during a snowfall event, including preferential deposition of snowfall (Lehning et al., 2008; Mott et al., 2010; Vionnet et al., 2017). 
Differences in the level of complexity of snowdriftpermitting models and associated driving wind fields influence the spatial and temporal ranges of application of these models. Due to their relatively low computational costs, models of the first category can be applied to simulate the snow cover evolution over entire snow seasons at a resolution between 25 and $200 \mathrm{~m}$ for regions covering hundreds of square kilometres (e.g., $210 \mathrm{~km}^{2}$ for Berhnardt et al., 2010; $1043 \mathrm{~km}^{2}$ for Gascoin et al., 2013; $3600 \mathrm{~km}^{2}$ for Sextone et al., 2018). On the other hand, models of the second category are usually restricted to the simulation of single blowing-snow events at resolution between $2 \mathrm{~m}$ and $50 \mathrm{~m}$ over regions covering tens of square kilometres (e.g., $1 \mathrm{~km}^{2}$ in Schneiderbauer and Prokop, 2011, $2.3 \mathrm{~km}^{2}$ in Mott and Lehning, 2010; $23 \mathrm{~km}^{2}$ in Vionnet et al., 2017). The study by Groot Zwaaftink et al. (2013) is an exception and relied on the Alpine 3D model (Lehning et al., 2008) to simulate the snow cover evolution at $10 \mathrm{~m}$ resolution over a region of $2.4 \mathrm{~km}^{2}$ of the Swiss Alps for an entire winter. All these snowdrift-permitting models used a gridded representation of the topography. Large-scale applications of these models over mountainous area are limited by the need to have a fixed and sufficiently high resolution over large areas even in regions where wind-induced snow transport is not active (valley bottom for example).

To overcome some of these limitations, Marsh et al. (2020a) developed a snowdrift-permitting scheme of intermediate complexity that solves the 3-D advection-diffusion blowing-snow transport on a variable resolution unstructured mesh. This scheme is implemented in the Canadian Hydrological Model (CHM; Marsh et al., 2020b). The landscape is discretized using a variable resolution unstructured mesh that allows an accurate representation of terrain heterogeneities with limited computation elements (Marsh et al., 2018). Marsh et al. (2020a) used the WindNinja diagnostic wind model (Forthofer et al., 2014) to build libraries of precomputed wind fields. Wagenbrenner et al. (2016) showed that WindNinja can be used to downscale wind field from atmospheric models running at a convection-permitting scale in complex terrain.

The objective of the present study is to develop and evaluate a novel strategy for multi-scale modelling of mountain snowpack over large regions and for entire snow seasons. Specifically, the following questions are asked. (1) Can efficient wind-downscaling approaches be used for blowing simulation? (2) Over large spatial extents, can lateral mass redistribution (blowing snow and avalanching) be ignored? (3) Can optical satellite imagery be used to diagnose model performances over large spatial extents? This modelling strategy combines (i) atmospheric forcing from the convectionpermitting Canadian numerical weather prediction (NWP) system, (ii) a downscaling module including wind fields from a high-resolution diagnostic wind model and (iii) the multiscale snowdrift-permitting model CHM running on an unstructured mesh. This modelling strategy was applied for a full winter around the Kananaskis Valley in the Canadian Rockies. Different model configurations were tested to assess the impact of the representation of physical processes in CHM as well as the complexity of the wind-downscaling scheme. Airborne lidar snow depth data and snow persistence indexes derived from Sentinel-2 images were used to evaluate the ability of the different CHM configurations to capture the elevation-snow depth relationship as well as snow redistribution around wind-exposed ridges. The paper is organized as follows: Sect. 2 presents the study area and the different observation datasets used in this study, and it also describes the CHM modelling platform, the winddownscaling strategy and the configurations of the CHM experiments. Section 3 evaluates the impact of the wind field downscaling and the quality of the snowpack simulations using airborne lidar snow depth data and snow persistence indexes; Sect. 4 discusses the main challenges associated with snowdrift-permitting modelling of mountain snowpack and associated limitations. Finally, concluding remarks are presented in Sect. 5.

\section{Data and methods}

\subsection{Study site}

This work studies the evolution of the mountain snowpack around the Kananaskis Valley of the Canadian Rockies, Alberta (Fig. 1). The study domain covers an area of $958 \mathrm{~km}^{2}$ and is characterized by a complex and rugged topography with elevations ranging from $1400 \mathrm{~m}$ at the Kananaskis Valley bottom in the northeastern part of the domain up to $3406 \mathrm{~m}$ at the summit of Mount Sir Douglas in the southern part of the region (Fig. 1b). Valley bottoms and lower slopes are predominately covered by needleleaf evergreen forest (Fig. 1a). Short shrubs and low vegetation are present near treeline whereas exposed rock surfaces, talus and grasses are found in the highest alpine elevations. The Kananaskis Valley hosts several meteorological stations that are part of the University of Saskatchewan's Canadian Rockies Hydrological Observatory (CRHO; https://research-groups.usask.ca/ hydrology/science/research-facilities/crho.php, last access: 29 January 2021) and is active for research in snow hydrology (e.g., MacDonald et al., 2010; Musselman et al., 2015; Pomeroy et al., 2012; 2016; Fang et al., 2019; Fang and Pomeroy, 2020). More details about these meteorological stations are given in Sect. 2.3.1.

\subsection{Model}

\subsubsection{Mesh generation}

The digital elevation model (DEM) from the Shuttle Radar Topography Mission-SRTM (EROS Center, 2017) at a resolution of $1 \operatorname{arcsec}(30 \mathrm{~m})$ was used as input to the mesher code (Marsh et al., 2018) to generate an unstructured, variable- 

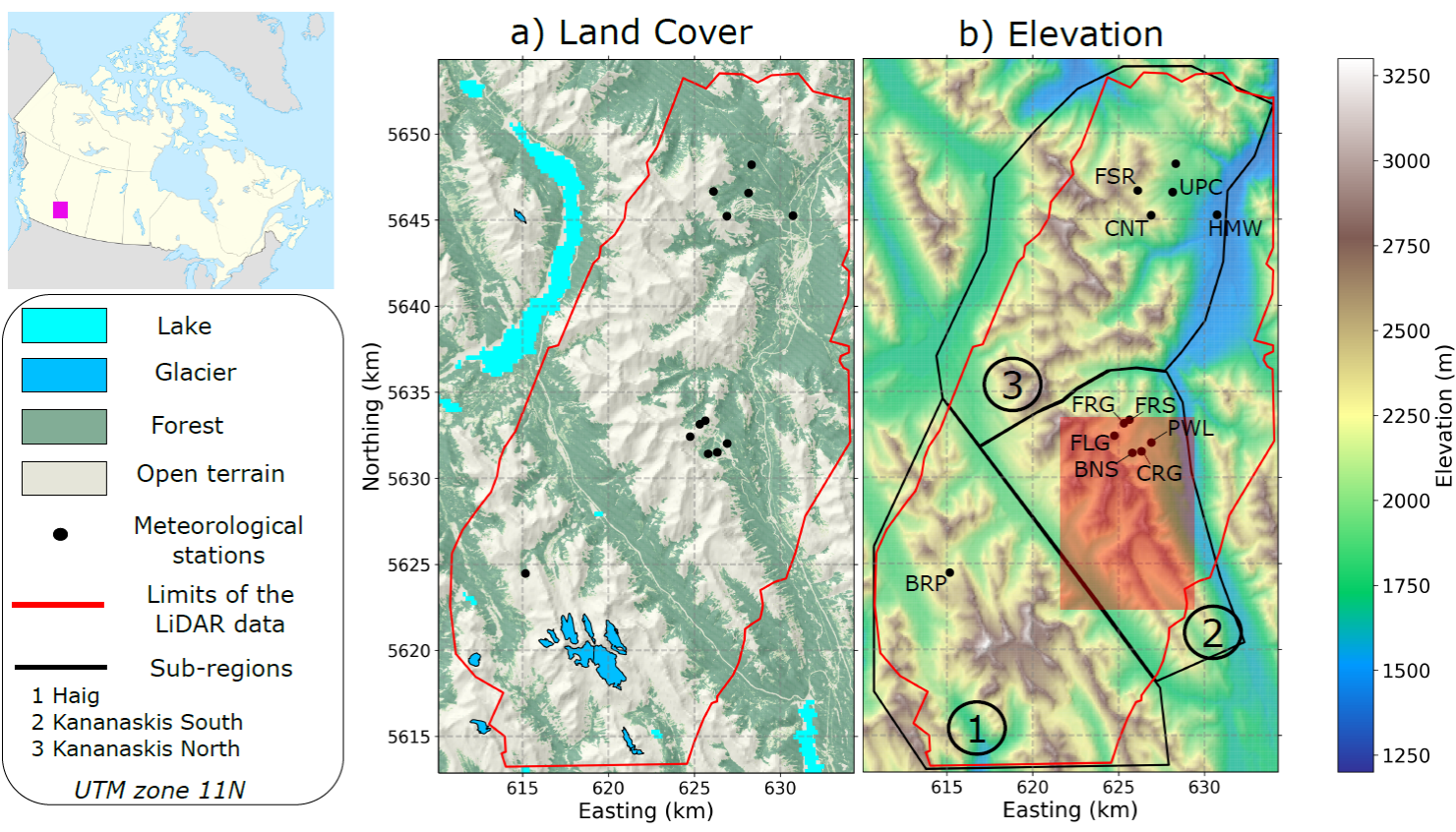

Figure 1. (a) Land cover map and (b) elevation map of the Kananaskis Valley, Alberta, Canada, study domain. The glacier mask is taken from the Randolph Glacier Inventory version 6.0 (Pfeffer et al., 2014). The red-shaded area corresponds to the area shown in Figs. 2, 3 , 6 and 10. The characteristics of the meteorological stations are given in Table 3. Areas labelled from 1 to 3 correspond to sub-regions used in the analysis of the results (see Sect. 2.3.2).

resolution triangular mesh over the Kananaskis domain (Fig. 1). In mesher, triangles are bounded with minimum and maximum areas and are generated to fulfil a given tolerance defined here as the root-mean-square error to the underlying topographic raster. This study uses a high-resolution mesh, denoted $M_{50}^{15}$ with a minimum triangle area of $50 \mathrm{~m} \times 50 \mathrm{~m}$ and a vertical tolerance of $15 \mathrm{~m}$. The characteristics of the generated mesh are given in Table 1. For the Kananaskis domain, 383200 raster grid cells with a $50 \mathrm{~m}$ resolution are required to represent the terrain, whereas 101700 triangles are used in $M_{50}^{15}$ (Fig. 2). Large triangles are found in valley bottoms of low topographic variability, whereas small triangles dominate in alpine terrain, close to ridges where windinduced snow redistribution is common.

A dataset of tall vegetation $(>5 \mathrm{~m})$ coverage, with a resolution of $30 \mathrm{~m}$ (Fig. 1a), was obtained from Hansen et al. (2013). These fractional values were applied to the triangular mesh via mesher by averaging the raster cells that correspond to each triangle and assigning this average to the triangle. Triangles with an average fraction of high vegetation larger than 0.5 were classified as forest.

\subsubsection{Snowpack model}

Distributed snowpack simulations over the triangular mesh of the study area were performed using the version of the Snobal scheme (Marks et al., 1999) implemented in CHM (Marsh et al. 2020b). Snobal has been used in numerous mountainous regions across North America (e.g., Garen and
Marks, 2005; Pomeroy et al., 2016; Hedrick et al., 2018). Snobal is a physically based snowpack model that approximates the snowpack with two layers. The surface layer was implemented here with a fixed thickness of $0.1 \mathrm{~m}$ and is used to estimate surface temperature for outgoing longwave radiation and turbulent heat fluxes. The second lower layer represents the remaining snowpack. For each layer, Snobal simulates the evolution of the snow water equivalent (SWE), temperature, density, cold content and liquid water content. The version of Snobal used in this study includes an improved algorithm for snow compaction that accounts for bulk compaction and temperature metamorphism (Hedrick et al., 2018). Snobal in CHM employs the snow albedo routine of Verseghy et al. (1993). The ground heat flux assumes heat flow to a single soil layer of known temperature and thermal conductivity. In these simulations, the soil temperature was set to $-4^{\circ} \mathrm{C}$ at $10 \mathrm{~cm}$ below the soil-snow interface. Marsh et al. (2020b) used the same value for Snobal simulations with CHM at the Marmot Creek Research Basin located further north in the Kananaskis Valley (Fig. 1).

CHM also includes a 3-D advection-diffusion blowingsnow transport and sublimation model (Marsh et al., 2020a): the 3-D Prairie Blowing Snow Model (PBSM-3D). This scheme uses a finite-volume method discretization on the unstructured mesh. It deploys the parameterization of $\mathrm{Li}$ and Pomeroy (1997) to determine the threshold wind speed for snow transport initiation as a function of air temperature and snow presence. It does not depend on the properties of sur- 
Table 1. Characteristics of the mesh used in this study. The vertical error corresponds the root-mean-square error to the underlying reference topographic raster.

\begin{tabular}{lccccc}
\hline $\begin{array}{l}\text { Name of } \\
\text { the mesh }\end{array}$ & $\begin{array}{c}\text { Minimum triangle } \\
\text { area }\left(\mathrm{m}^{2}\right)\end{array}$ & $\begin{array}{c}\text { Maximum triangle } \\
\operatorname{area}\left(\mathrm{m}^{2}\right)\end{array}$ & $\begin{array}{c}\text { Median triangle } \\
\text { area }\left(\mathrm{m}^{2}\right)\end{array}$ & $\begin{array}{c}\text { Vertical error } \\
(\mathrm{m})\end{array}$ & $\begin{array}{c}\text { Number of } \\
\text { triangles }\end{array}$ \\
\hline$M_{50}^{15}$ & $50 \times 50$ & $250 \times 250$ & $63 \times 63$ & 15 & 101700 \\
\hline
\end{tabular}

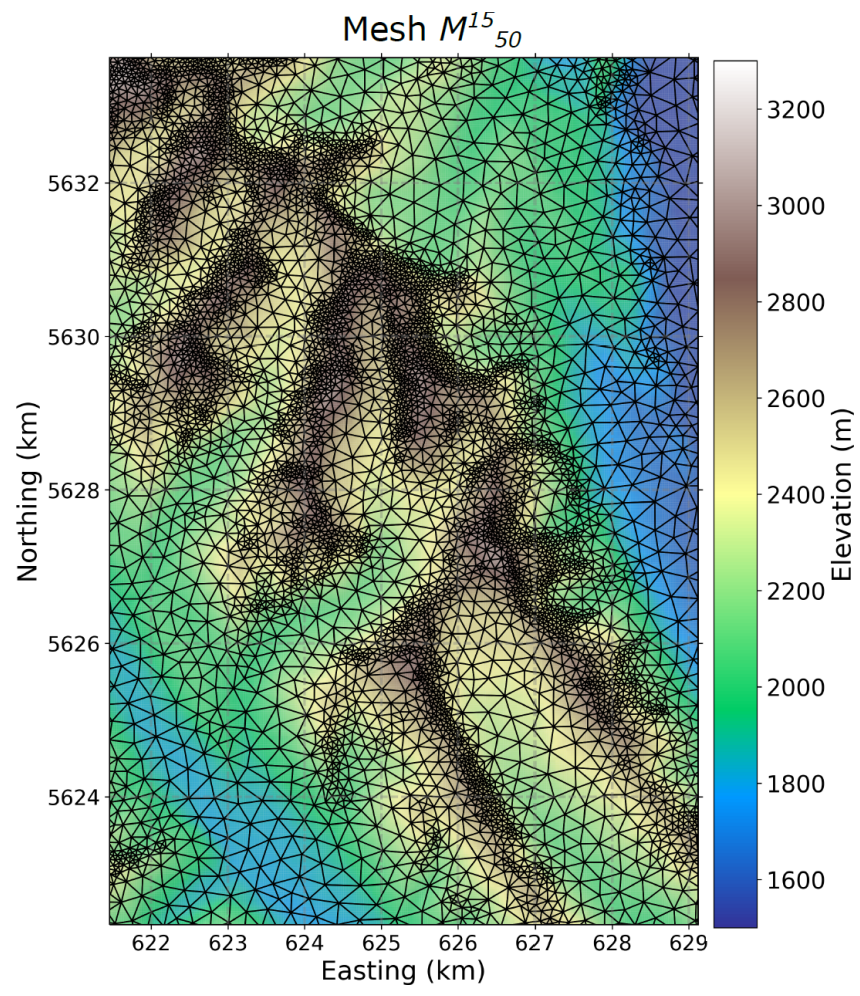

Figure 2. Variable-resolution triangular mesh used in this study over a sub-area of the Kananaskis domain. The location of this subarea corresponds to the red-shaded area shown in Fig. 1b. The underlining DEM was taken from the SRTM mission at 1 arcsec.

face snow (e.g., density, liquid water content) simulated by Snobal (see Sect. 4.4 for a discussion on the limitation of this approach). In the case of blowing-snow occurrence, the steady-state saltation parameterization of Pomeroy and Gray (1990) is used to compute the mass concentration in the saltation layer. The concentration in the saltation layer is impacted by shear stress partitioning due to the presence of vegetation (such as shrubs) and the upwind fetch. Upwind fetch is calculated for each triangle of the mesh using the fetchr parameterization of Lapen and Martz (1993) and is used to reduce the mass concentration in the saltation layer in regions where flow is developing. The saltation layer acts as a lower boundary condition for the suspension layer, which is discretized with a user-defined number of layers to resolve the gradient of concentration of blowing-snow particles in the suspension layer. For each layer, PBSM-3D solves the evolution of the concentration of blowing-snow particles accounting for advection, turbulent diffusion, sedimentation and mass loss due to sublimation based on the parameterizations proposed by Pomeroy and Male (1992) and Pomeroy et al. (1993). At a given time step, erosion and deposition rates are computed as the spatial divergence of the saltation and suspension fluxes, and the snowpack simulated by Snobal is updated accordingly. In this study, 10 layers were used for a total height of the suspension layer of $5 \mathrm{~m}$ as in Marsh et al. (2020a). Snowfall over complex terrain is calculated by GEM according to its microphysics scheme (Milbrandt et al., 2016). CHM does not simulate explicitly preferential deposition of snowfall (Lehning et al., 2008; Mott et al., 2018). New snow is added to the surface layer in Snobal and, if wind speeds exceed the threshold wind speed, it is transported in the saltation and suspension blowing-snow layers by PBSM-3D.

In steep alpine terrain, gravitational snow transport strongly affects the spatial variability of the snowpack (e.g., Sommer et al., 2015) and the mass balance of glaciers (Mott et al., 2019) and modifies the runoff behaviour of alpine basins (Warscher et al. 2013). For these reasons, the SnowSlide scheme (Bernhard and Schulz, 2010) was implemented in CHM. SnowSlide is a simple topographically driven model that simulates the effects of gravitational snow transport. SnowSlide uses a snow-holding depth that decreases exponentially with increasing slope angle, limiting snow accumulation in steep terrain. SnowSlide was initially developed for regular gridded rasters and has been adapted here to the unstructured triangular mesh used by CHM. SnowSlide operates from the highest triangle of the mesh to the lowest one. If the snow depth exceeds the snow-holding capacity for a given triangle, excess snow is redistributed to the lower adjacent triangles, proportionally to the elevation difference between the neighbouring triangles and the original one. SnowSlide uses the total elevation (snow depth plus surface elevation) to operate. In this study, the default formulation of the snow-holding depth proposed by Bernhardt and Schulz (2010) is used, which leads to a maximal snow thickness (taken perpendicular to the slope) of $3.08 \mathrm{~m}, 1.11 \mathrm{~m}$, $0.45 \mathrm{~m}$ and $0.15 \mathrm{~m}$ for slopes of $30^{\circ}, 45^{\circ}, 60^{\circ}$ and $75^{\circ}$, respectively.

The impact of the presence of forest vegetation on snow interception, sublimation, snowpack accumulation and melt energetics is represented in CHM using the same canopy module as in the Cold Region Hydrological Model (CRHM; Ellis et al., 2010; Pomeroy et al. 2012). This module used leaf 
area index and canopy closure to compute the effect of forests on shortwave and longwave irradiance at the snow surface. Snow interception and sublimation of intercepted snow are also represented following Hedstrom and Pomeroy (1998). In this study, the canopy module was activated for the triangles covered by forest as described in Sect. 2.2.1.

\subsubsection{Atmospheric forcing}

Snobal and PBSM-3D require the following atmospheric forcing: air temperature, humidity, wind speed, wind direction, liquid and solid precipitation rates, and longwave and shortwave irradiance. Due to the scarcity of the network of meteorological stations in the region (Fig. 1), hourly atmospheric forcings were obtained from the HighResolution Deterministic System (HRDPS; Milbrandt et al., 2016). HRDPS is the high-resolution NWP system running the Global Environmental Multiscale Model (GEM) operationally over Canada at $2.5 \mathrm{~km}$ grid spacing. Successive HRDPS forecasts from the 00:00 and 12:00 UTC analysis time at 6 to $17 \mathrm{~h}$ lead time were extracted over the region and combined together to generate a continuous atmospheric forcing. Previous studies have also used distributed forcing data from NWP systems to drive snowpack models in mountainous terrain since these data can often represent the complex interactions between topography and atmospheric flow better than sparse meteorological measurements (Quéno et al., 2016; Vionnet et al., 2016; Havens et al. 2019; Lundquist et al., 2019; Fang and Pomeroy, 2020).

The HRDPS atmospheric forcing at $2.5 \mathrm{~km}$ grid spacing was downscaled to the triangles of the CHM mesh. Horizontal interpolation was first applied using inverse-distance weighting from the closest four HRDPS grid points. Corrections for elevation differences were then applied to adapt the HRDPS meteorological forcing to the high-resolution topography of the CHM mesh. Constant monthly lapse rates were used to adjust HRDPS $2 \mathrm{~m}$ air temperature and humidity (Kunkel, 1989; Shea et al., 2004). HRDPS temperature was reduced (increased) if the elevation of the triangle is higher (lower) than the elevation of the HRDPS grid points. Precipitation amounts were not modified to account for elevation difference as it was assumed that HRDPS already captures the main orographic effects affecting mountain precipitation (Lundquist et al., 2019). The precipitation adjustment function of Liston and Elder (2006) has been tested but it led to strong overestimation of snow depth at high elevation (not shown), suggesting that this factor may not be adapted to account for the subgrid variability of precipitation amount within a $2.5 \mathrm{~km}$ grid. A cosine correction was then applied to adjust precipitation falling on an inclined triangle for massconservation purposes (Kienzle, 2011). Downscaled temperature and humidity were finally used to compute the precipitation phase with the psychrometric energy balance method of Harder and Pomeroy (2013) that performed well in the Kananaskis Valley. Direct and diffuse solar irradiance were taken from the HRDPS forecast, and direct irradiance was corrected for slope and aspect as described in Marsh et al. (2012). Local terrain shadowing and its impact on shortwave irradiance were calculated using the algorithm of Dozier and Frew (1990) adapted for unstructured meshes as described in Marsh et al. (2020b). Longwave irradiance was adjusted for elevation difference using the climatological lapse rate of Marty et al. (2002). Finally, wind speed and direction were taken from the lowest HRDPS prognostic level at $40 \mathrm{~m}$ above the surface and were downscaled to the CHM mesh using the strategy described in the next section.

\subsubsection{Wind field downscaling}

Mountain wind fields are notoriously difficult to observe and model (Davies et al., 1995), and obtaining high-resolution wind fields constitutes one of the greatest challenges for blowing-snow models in mountainous terrain (e.g., Mott and Lehning, 2010; Vionnet et al., 2014; Musselman et al., 2015; Réveillet et al., 2020). In the context of this study, hourly HRDPS near-surface wind fields at the $2.5 \mathrm{~km}$ scale were downscaled to the CHM mesh over the full duration of the simulations ( 1 water year). This required a computationally efficient wind-downscaling method. Therefore, the winddownscaling strategy used in this study was derived from the method proposed by Barcons et al. (2018) for mesoscaleto-microscale downscaling of near-surface wind fields. This method combines precomputed microscale simulations with a mesoscale forecast using transfer functions. In their study, Barcons et al. (2018) combined the Weather Research and Forecast mesoscale model at $3 \mathrm{~km}$ grid spacing and the AlyaCFDWind microscale model at $40 \mathrm{~m}$ grid spacing. In our study, microscale wind simulations were generated with the WindNinja model. WindNinja is a mass-conserving diagnostic wind model, primarily designed to simulate mechanical effects of terrain on the flow (Forthofer et al., 2014). Forthofer et al. (2014) showed that the model captures important terrain-induced flow features, such as ridgetop acceleration or terrain channelling, and can improve wildfire spread predictions in complex terrain. Wagenbrenner et al. (2016) used the model to directly downscale near-surface wind forecasts from NWP systems in complex terrain.

The application and extension of the Barcons et al. (2018) approach for use on an unstructured mesh and to account for direction perturbations are detailed below. First, to build the wind map library, WindNinja was run at $50 \mathrm{~m}$ resolution over the Kananaskis domain (Fig. 1). As WindNinja uses a regular grid, the input topography was taken from the same SRTM DEM at $30 \mathrm{~m}$ grid spacing that was used to build the CHM mesh (Sect. 2.2.1). WindNinja used a spatially constant roughness length $\left(z_{0}=0.01 \mathrm{~m}\right)$ representative of snow-covered terrain in alpine topography (Mott et al., 2010; Mott and Lehning, 2010), and vegetation effects were introduced later in the downscaling procedure, as described below. WindNinja simulations were carried out for 24 initial 
wind directions (each $15^{\circ}$ ) with an initial wind speed at $40 \mathrm{~m}$ above the surface set to $10 \mathrm{~m} \mathrm{~s}^{-1}$. The height of $40 \mathrm{~m}$ corresponds to the lowest HRDPS prognostic level.

Then, for each wind direction in the wind map library, the transfer function $f$ was computed for use in the downscaling procedure given as

$f=\frac{U_{\mathrm{WN}}}{\left\langle U_{\mathrm{WN}}\right\rangle_{L}}$,

where $U_{\mathrm{WN}}$ is the local wind speed $\left(U_{\mathrm{WN}}=\sqrt{u_{\mathrm{WN}}^{2}+v_{\mathrm{WN}}^{2}}\right)$, $u_{\mathrm{WN}}$ and $v_{\mathrm{WN}}$ are the horizontal components of the wind at $50 \mathrm{~m}$ resolution, and $\left\langle U_{\mathrm{WN}}\right\rangle_{L}$ is the spatial average of $U_{\mathrm{WN}}$ over an area of size $L \times L$. By construction, when $L$ tends towards $0, f$ tends towards 1 . As $L$ increases, $f$ incorporates the local wind fluctuation induced by the microscale terrain features (Barcons et al., 2018). A value of $L=1000 \mathrm{~m}$ was used in this study in agreement with the finding of Barcons et al. (2018) in complex terrain. Note that Barcons et al. (2018) used a circle instead of a square to compute the spatial average of the wind speed. Thus, $f$ acts as a speedup/slowdown factor that accounts for topographic impacts on wind speed. Only one value for the initial wind speed was used to build the wind library due to the insensitivity of the transfer function to the initial wind speed found with WindNinja.

To account for impacts on direction, the following approach was taken. The rasters of the wind map library containing the horizontal $u$ and $v$ wind components and the transfer function $f$ for each initial wind direction were applied to the triangles of the unstructured mesh using the mesher code (Marsh et al., 2018). At each CHM time step, the HRDPS $u_{\text {HRDPS }}$ and $v_{\text {HRDPS }}$ wind components were spatially interpolated to the triangles' centres with an inversedistance interpolant using the four closest HRDPS grid points. For each triangle, the interpolated HRDPS wind direction, $\theta_{\text {HRDPS }}$, was then reconstructed from the interpolated HRDPS wind components, $u_{\text {HRDPS_int }}$ and $v_{\text {HRDPS_int. This }}$ direction was used to select the two sets of precomputed microscale wind components with the wind directions $\varphi_{1}$ and $\varphi_{2}$ that bound $\theta_{\text {HRDPS }}$ (i.e., $\varphi_{1}<\theta_{\text {HRDPS }}<\varphi_{2}$ ). These selected microscale wind components including the local terrain effect were then linearly interpolated and recombined to obtain the downscaled wind direction $\theta_{\text {Down }}$. The transfer functions corresponding to the wind directions $\varphi_{1}$ and $\varphi_{2}$ were also linearly combined to obtain the final transfer function, $f_{\text {down }}$. It was finally applied to scale the modulus of the interpolated HRDPS wind speed and derive the final downscaled wind speed as in Barons et al. (2018):

$U_{\text {Down }}=f_{\text {down }} \sqrt{u_{\text {HRDPS_int }}^{2}+v_{\text {HRDPS_int }}^{2}}$.

Wind speeds were then adjusted to $10 \mathrm{~m}$ wind speeds using the Prandtl-von Kármán logarithmic wind profile and modified to include vegetation interactions using the vegetation cover of the triangle as defined in Sect. 2.2.1. Fetch effects due to the presence of upstream vegetation are not taken into account when adjusting the wind speed.

Forthofer et al. (2014) and Wagenbrenner et al. (2016, 2019) showed that the mass-conserving version of WindNinja has difficulties simulating lee-side recirculation where flow separation occurs. This difficulty is due to the absence of a momentum equation in the WindNinja flow simulation (Forthofer et al., 2014). As lee-side flow strongly influences snow accumulation (e.g., Gerber et al., 2017), an additional and optional step was added to the wind-downscaling procedure described above. It consisted of a modification of the transfer functions $f_{\text {down }}$ to reduce wind speed in leeward areas prone to flow separation. At each CHM time step, leeward areas were identified using the Winstral topographic parameter $S x$ (Winstral and Marks, 2002; Winstral et al., 2017), computed at each triangle using the downscaled wind direction, $\theta_{\text {Down }}$. The $S x$ algorithm examines all triangles along a fixed search line emanating from the triangle of interest to determine which triangle has the greatest upward slope relative to the triangle of interest. Positive $S x$ values indicate sheltering features whereas negative $S x$ values indicate that the triangle of interest height is the highest cell along the search line and is topographically exposed. In this study, the $S x$ algorithm used a search distance of $300 \mathrm{~m}$, as in Winstral et al. (2017). Triangles with $S x$ values larger than $20^{\circ}$ were considered susceptible to flow separation in agreement with previous studies on the onset of flow separation in complex terrain (e.g., Wood, 1995). For these triangles, the transfer function, $f_{\text {down }}$, was set to a value of 0.25 (Winstral et al., 2009). Note finally that a mass- and momentum-conserving version of WindNinja is also available (Wagenbrenner et al., 2019). Wagenbrenner et al. (2019) have shown that momentum conservation improved flow simulation at windward and leeward locations compared to the mass-conserving version, but numerical instabilities made this version of the code unusable in the complex topography of the Canadian Rockies.

\subsubsection{Model experiments}

A set of CHM experiments were designed to assess the effect of the wind field downscaling and the impact of process representation on snowpack simulations at snowdriftpermitting scales (Table 2). A reference CHM configuration including wind downscaling accounting for recirculation and gravitational and blowing-snow redistribution was first defined ( $W n d \operatorname{Tr} A v R c$ ). A stepwise model falsification was then used, removing the following processes from the model: (i) recirculation effects in the wind-downscaling procedure (WndTr Av NoRc), (ii) blowing-snow redistribution with PBSM-3D (NoWndTr Av), (iii) gravitational snow redistribution with SnowSlide (NoWndTr NoAv), (iv) wind downscaling with WindNinja (NoDown). Note that all the CHM experiments considered in this study account for the effects of terrain slope and aspect on incoming shortwave radiation. 
These simulations covered the period from 1 September 2017 to 31 August 2018 to fully capture snow accumulation and ablation in the region. For each experiment, CHM outputs were rasterized to a $50 \mathrm{~m} \times 50 \mathrm{~m}$ raster for model evaluation. This rasterization was done via the GDAL rasterization capabilities (GDAL/OGR contributors, 2020). In short, this algorithm takes the triangle geometry in conjunction with an output raster (with given cell sizes and domain extent) and resolves which raster cells correspond to each triangle. In the case that two triangles share an output cell, an overwrite is used by the algorithm. The $50 \mathrm{~m} \times 50 \mathrm{~m}$ area was selected as it corresponds to the minimal triangle area for high resolution used in this study (Table 1).

\subsection{Data and evaluation methods}

\subsubsection{Meteorological observations}

Hourly meteorological data collected at CRHO stations were used to evaluate the precipitation and wind fields driving CHM (Table 3). These stations include those in Marmot Creek Research Basin (Fang et al., 2019) and Fortress Mountain Snow Laboratory (Harder et al., 2016) (Table 3 and Fig. 1), covering an elevation range from 1492 to $2565 \mathrm{~m}$. Table 3 also provides the topographic position index (TPI) at the position of the stations (Table 3 ) as this metric provides a quantification of each station's elevation relative to its surroundings. In this study, TPI was defined as in Winstral et al. (2017) and consists of the difference between each station's elevation on a $50 \mathrm{~m}$ raster minus the mean of all pixel elevations located within a $2 \mathrm{~km}$ radius from the station. Hourly meteorological data were obtained from quality-controlled 15 min observations using the same method as in Fang et al. (2019). In particular, solid precipitation data were corrected from wind-induced undercatch using the method proposed by Smith (2007). Simulated wind speeds were corrected to the sensor height of each station (including snow depth) using a standard log-law for the vertical profile of wind speed near the surface and an aerodynamic roughness of $1 \mathrm{~mm}$ typically found in snow-covered alpine terrain (e.g., Naaim Bouvet et al., 2010).

\subsubsection{Airborne lidar snow depth data}

Airborne laser scanning (ALS) surveys were performed over the Kananaskis region on 5 October 2017 (late summer scan) and on 27 April 2018 (winter scan) using a Riegl Q780 infrared $(1024 \mathrm{~nm})$ laser scanner with a dedicated Applanix POS AV Global Navigation Satellite System (GNSS) inertial measurement unit (IMU). The Q-780 scanner was flown at heights of approximately $2500 \mathrm{~m}$ above the terrain that yielded swath widths of 2000 to $3000 \mathrm{~m}$. Postprocessing of the ALS survey flight trajectory yielded vertical and horizontal positional uncertainties of $\pm 15 \mathrm{~cm}(1 \sigma)$. Post-processed point cloud data were exported into LAS files, and LAStools (https://rapidlasso.com/lastools/, last access: 29 January 2021) was used to generate $5 \mathrm{~m}$ resolution digital elevation models (DEMs). The summer and winter DEMs were co-registered to minimize slope and aspectinduced errors (Nuth and Kääb, 2011). Additional details about the processing workflow over snow-covered terrain can be found in Pelto et al. (2019). To estimate uncertainties on the snow depth retrieval, snow-free areas that included peaks and road surfaces were identified in a $3 \mathrm{~m}$ satellite imagery (Planet Scope) for 27 April 2018. Analysis of elevation change over these snow-free surfaces (34 comparison points across all elevation) indicated an average (median) elevation change of $-4.1 \mathrm{~cm}(0.5 \mathrm{~cm})$ and a standard deviation of $19.8 \mathrm{~cm}$. The median absolute deviation reached $8.0 \mathrm{~cm}$. The DEM of snow depth was masked to only include nonglacierized terrain (Fig. 1b) and to exclude any areas of elevation change that was less than $0 \mathrm{~m}$ and greater than $20 \mathrm{~m}$; elevation change beyond these values is considered an outlier (Grünewald et al., 2014) and can arise from steep terrain that was effectively in the shadow of the laser scanner. For model evaluation, the $5 \mathrm{~m}$ snow depth map was then resampled over the same $50 \mathrm{~m}$ raster as the CHM output, taking for each cell of the $50 \mathrm{~m}$ raster the average of all non-masked cells in the $5 \mathrm{~m}$ snow depth map. Cells of the $50 \mathrm{~m}$ raster that contained more than $75 \%$ of masked cells in the $5 \mathrm{~m}$ snow depth map were masked out. In addition, grid points covered by glaciers identified in the Randolph Glacier Inventory (Pfeffer et al., 2014) were removed from the analysis since elevation change over these surfaces is also influenced by ice dynamics (Pelto et al., 2019). Finally, forested pixels identified using the global database of Hansen et al. (2013) at $30 \mathrm{~m}$ grid spacing were masked out as well since this study focuses on snow redistribution processes in open terrain.

The distributions of simulated and observed snow depths were compared for different $200 \mathrm{~m}$ elevation bands for three sub-areas of the Kananaskis domain (Fig. 1b): (i) Kananaskis North, (ii) Kananaskis South and (iii) Haig. These three sub-areas were characterized by a different mean (standard deviation) of observed snow depths: $0.90 \mathrm{~m}(0.82 \mathrm{~m})$ for Kananaskis North, $1.32 \mathrm{~m}$ (1.03 m) for Kananaskis South and $2.00 \mathrm{~m}(1.33 \mathrm{~m})$ for Haig. For each elevation band, the rootmean-squared error (RMSE) and the Wasserstein distance of order 1, $W_{1}$ (Rüschendorf, 1985), were used to quantify the agreement between the simulated and the observed distributions. $W_{1}$ is defined as

$W_{1}(\mathrm{~s}, \mathrm{o})=\int_{-\infty}^{+\infty}|\mathrm{S}(\mathrm{s})-\mathrm{O}(\mathrm{o})|$,

where $\mathrm{s}$ and $\mathrm{o}$ are the simulated and observed snow depth distributions and $\mathrm{S}$ and $\mathrm{O}$ the corresponding cumulative distribution functions. $W_{1}$ has the same unit as the variable considered (here metres for snow depth), $d$ and a perfect match between the distribution led to $W_{1}=0$. For each sub-area, simulated and observed snow depth distributions were also 
Table 2. CHM simulations (experiments) used in this study. Rc indicates CHM simulations using wind fields from the downscaling method accounting for wind speed reduction in leeward areas. HRDPS refers to the High Resolution Deterministic Prediction System and WN to WindNinja. See text for more details.

\begin{tabular}{llll}
\hline Name & Driving wind field & $\begin{array}{l}\text { Gravitational } \\
\text { redistribution }\end{array}$ & $\begin{array}{l}\text { Wind-induced } \\
\text { snow transport }\end{array}$ \\
\hline NoDown & HRDPS & No & No \\
NoWndTr NoAv & HRDPS + WN + Rc & No & No \\
NoWndTr Av & HRDPS + WN + Rc & Yes & No \\
WndTr Av NoRc & HRDPS + WN & Yes & Yes \\
WndTr Av Rc & HRDPS + WN + Rc & Yes & Yes \\
\hline
\end{tabular}

Table 3. Meteorological stations used for wind evaluation. TPI refers to the topographic position index and is defined as the difference between the elevation of the station minus the mean elevation within a $2 \mathrm{~km}$ radius from this station. The location of the stations is shown in Fig. 1.

\begin{tabular}{llcrcr}
\hline Full name & Code & $\begin{array}{c}\text { Latitude } \\
\left({ }^{\circ}\right)\end{array}$ & $\begin{array}{r}\text { Longitude } \\
\left({ }^{\circ}\right)\end{array}$ & $\begin{array}{r}\text { Elevation } \\
(\mathrm{m})\end{array}$ & $\begin{array}{r}\text { TPI } \\
(\mathrm{m})\end{array}$ \\
\hline Centennial Ridge & CNT & 50.9447 & -115.9370 & 2470 & 248 \\
Fisera Ridge & FSR & 50.9568 & -115.2044 & 2325 & -10 \\
Hay Meadow & HMW & 50.9441 & -115.1389 & 1492 & -33 \\
Fortress Ledge & FLG & 50.8300 & -115.2285 & 2565 & 216 \\
Fortress Ridge & FRG & 50.8364 & -115.2209 & 2327 & 99 \\
Fortress Ridge South & FRS & 50.8382 & -115.2158 & 2306 & 129 \\
Canadian Ridge & CRG & 50.8215 & -115.2063 & 2211 & 68 \\
Burtsall Pass & BRP & 50.7606 & -115.3671 & 2260 & -90 \\
\hline
\end{tabular}

compared as a function of slope orientation in the upper slopes using bias and $W_{1}$ to provide a specific assessment of model performances in regions particularly exposed to windinduced snow transport. Upper slopes in the $50 \mathrm{~m}$ raster were identified using the TPI as defined above. Regions with TPI greater than $150 \mathrm{~m}$ were classified as upper slopes.

\subsubsection{Sentinel-2 snow cover maps}

Wayand et al. (2018) suggested that snow persistence indices from Sentinel-2 images present a strong potential for the evaluation of distributed snow models in mountainous areas. Hence, maps of the snow-covered area from the Copernicus Sentinel-2 satellite mission (Drusch et al., 2012) at $20 \mathrm{~m}$ resolution and at $5 \mathrm{~d}$ revisit time were considered as complementary data to evaluate CHM simulations. Sentinel2 images from 1 September 2017 to 31 August 2018 were processed using the snow retrieval algorithm that is currently used to produce the Theia Snow collection (Gascoin et al., 2019). First, orthorectified top-of-atmosphere (level 1C) products were processed to bottom-of-atmosphere reflectances (level 2A) using the MAJA software version 3.1 (Hagolle et al., 2017). MAJA output cloud mask and flatsurface reflectances were used as input to the LIS software version 1.5. The LIS algorithm is based on the normalized difference snow index (Dozier, 1989) and uses a digital elevation model to better constrain the snow detection (Gascoin et al., 2019). Hansen et al. (2013) global forest product was used to mask out pixels with a tree cover density larger than $50 \%$ since the snow retrieval algorithm is not adapted to the detection of the snow cover in dense forest areas where the ground is obstructed by the canopy. To further avoid misclassifications due to forest obstruction or turbid water surfaces, the DEM was used to mask out pixels below $2000 \mathrm{~m}$. The final snow product provided the following classification for each pixel: (i) no snow, (ii) snow, (iii) cloud including cloud shadows and (iv) no data.

Sentinel-2 snow cover maps at $20 \mathrm{~m}$ resolution were resampled to the same $50 \mathrm{~m}$ raster as the CHM output using a median filter. Maps of observed snow persistence (SP) indices at $50 \mathrm{~m}$ resolution were then derived following Macander et al. (2015) and Wayand et al. (2018). SP represents for each pixel the ratio between the number of snow-covered days and the total number of clear-sky observations (snow or no snow). SP was computed using images from 1 April 2018 to 31 August 2018 and SP ranges from 0 (always snow-free) to 1 (always snow-covered). Over the study period, the mean number of clear-sky observations per pixel reached $18.6 \mathrm{~d}$. The same calculation was carried out with CHM outputs to derive maps of simulated snow persistence indices. The same dates as the Sentinel-2 maps were used, and for each date, the Sentinel-2 cloud and no-data masks were applied to make sure that the same pixels and dates were considered when 
computing observed and simulated SP indices. A grid cell was considered snow-covered if the snow thickness exceeded $5 \mathrm{~cm}$ (Gascoin et al., 2019). The agreement between the simulated and the observed SP distributions was quantified as a function of elevation and slope orientation in the upper slopes for the same three sub-regions considered for snow depth (i.e., Kananaskis North, Kananaskis South and Haig). Grid cells that were not covered by forest in the observations and in the simulations were considered for the analysis.

\section{Results}

The evaluation of the different wind-downscaling methods is described in Sect. 3.1. The quality of the snowpack simulations is then assessed in Sect. 3.2 using airborne lidar snow depth data and snow persistence indexes. A special emphasis is placed on the ability of the model to capture the elevationsnow depth relation as well as snow redistribution around wind-exposed ridges.

\subsection{Wind field downscaling}

Figure 3 compares the near-surface wind field obtained from a simple bilinear interpolation of the HRDPS wind field (Fig. 3a) with the downscaled wind field obtained with (Fig. 3c) and without (Fig. 3b) the wind speed reduction in leeward areas. HRDPS provided a smooth wind field with relatively higher wind speeds in the northwestern part of the region characterized by high relief (Fig. 3a) compared to the rest of the area. HRDPS did not reflect the local terrain information due to a horizontal resolution of $2.5 \mathrm{~km}$. Combining the HRDPS wind field with precomputed microscale WindNinja simulations strongly altered the near-surface wind field (Fig. 3b). The downscaled field contained the general pattern from the HRDPS modulated by the local-scale terrain information added by WindNinja and reproduced some typical features of atmospheric flow in complex terrain (e.g., Raderschall et al., 2008). In particular, the topography surrounding the main valleys channelled the downscaled atmospheric flow, as illustrated by downscaled wind directions aligned parallel to the main valley axes. The presence of ridge crests generated cross-ridge downscaled flow and associated crest wind speed-up. Downscaled wind speeds were the same on the windward and leeward sides of crests, however, as expected with the mass-conserving version of WindNinja (Wagenbrenner et al., 2016, 2019). For this reason, an additional downscaling step using the Winstral parameter to reduce the wind speed in leeward areas was considered as described in Sect. 2.2.4 (Fig. 3c). Blue arrows in Fig. 3c correspond to leeward areas sheltered from the atmospheric flow and characterized by low downscaled wind speed. This additional downscaling step did not modify the wind direction in these areas.
Figure 4 gives the error metrics for the wind speed (bias and RMSE) between the CHM simulations and observations at eight automatic weather stations. The HRDPS without downscaling overestimated wind speed (positive bias) at all stations, except the CNT station. This station is located on an exposed crest and presents the largest TPI value among the stations used for model evaluation (Table 3). Downscaling wind to the CHM mesh using WindNinja microscale winds (experiment HRDPS + WN) improved the error metrics (decrease in bias in absolute value and decrease in RMSE) at four of the stations (BRP, HMW, FSR and CNT). In particular, the wind downscaling reduced the negative bias found in the HRDPS for the wind-exposed CNT station, presumably because the downscaling captures ridge crest speed-up of wind velocity. Decreased model performances were found at four neighbouring stations located around the Fortress Mountain Snow Laboratory, however (CRG, FRG, FRS and FLG; Fig. 3a). At these stations located along local ridges, the wind downscaling, accounting for crest speed-up, increased the wind speed and led to a larger positive bias than the default HRDPS (Fig. 3b). Accounting for the formation of zones of low wind speed in leeward areas in the downscaling method (experiment HRDPS $+\mathrm{WN}+\mathrm{Rc}$ ) was neutral at two stations located at low elevation (BRP and HMW) and improved results at all remaining stations, except at CNT. Indeed, a strong degradation of model performance was found at this station since it is placed on a sheltered triangle next to the crest on the CHM mesh, leading to an unrealistic reduction of downscaled wind speed.

The wind-downscaling method also modified the general wind direction (Figs. 3 and 5). Prevailing winds during the study originated from the south $\left(\mathrm{S} ; 180^{\circ}\right)$ to southwest $(\mathrm{SW}$, $225^{\circ}$ ) at most of the stations, whereas the HRDPS without downscaling provided wind mainly from the SW-west $\left(\mathrm{W}, 270^{\circ}\right)$. Improvements in wind direction when combining HRDPS and WindNinja were found for about half of the meteorological stations. The large error at the CRG station illustrated that none of the wind simulation considered in this study captured the complex features of the atmospheric flow around the Fortress Mountain Snow Laboratory (Fig. 3a).

\subsection{Snowpack simulations}

\subsubsection{Observed and simulated snow distributions}

To assess the ability of CHM to simulate small-scale features of snow accumulation and transport in alpine terrain, ALSderived snow depths were compared with simulated snow depths for different CHM experiments for a sub-region of approximately $77 \mathrm{~km}^{2}$ (Fig. 6). Observed snow depth was characterized by strong spatial variability (Fig. 6a). Shallow snow cover (generally less than $1 \mathrm{~m}$ ) was found in the upper south- to northeast-facing slopes that were primarily exposed to wind (Fig. 5). Snow accumulated on the leeward side of these slopes (purple contours in Fig. 6a). Thick snow 
(a) HRDPS

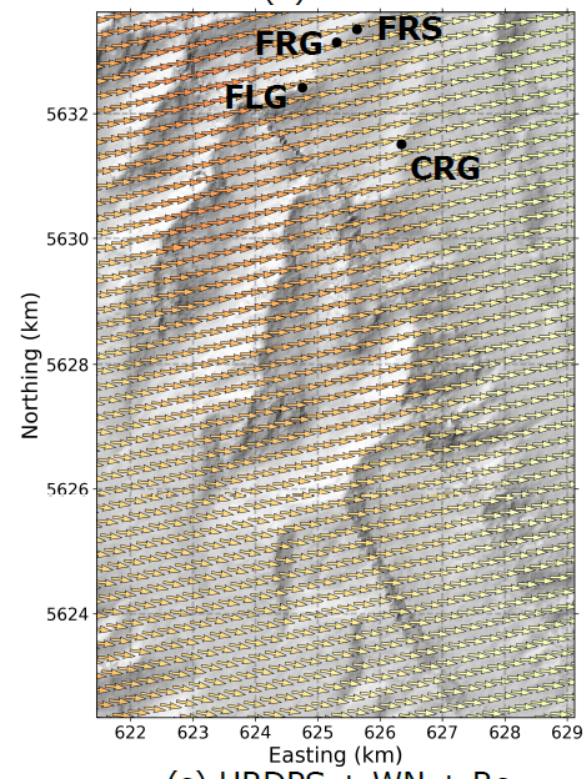

(c) HRDPS + WN + Rc

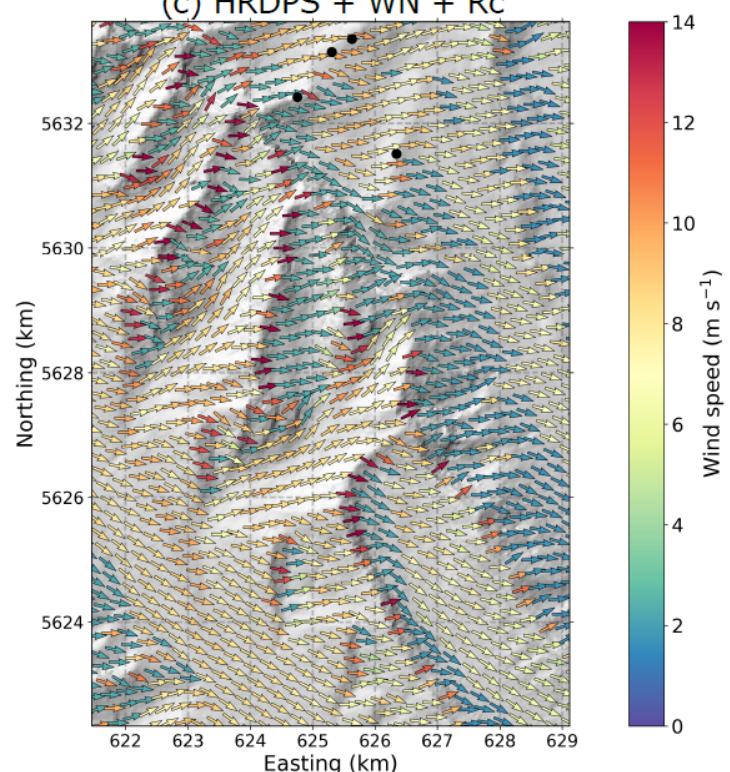

(b) HRDPS + WN

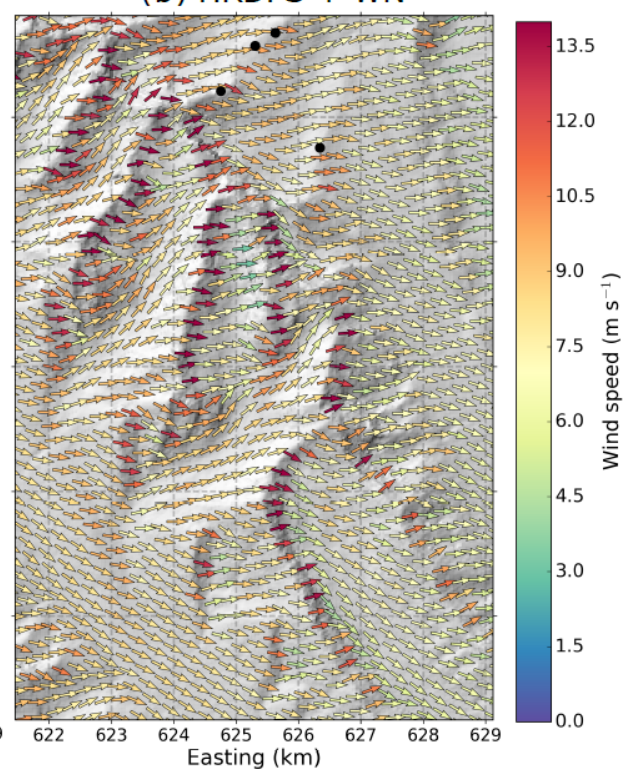

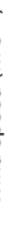 \\ (1)}




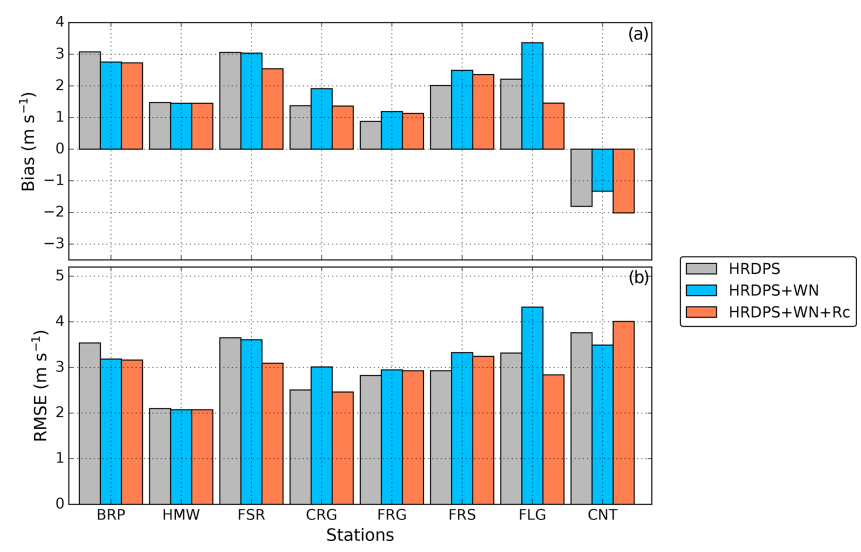

Figure 4. Evaluation of simulated wind speed using different downscaling methods: (a) bias and (b) root-mean-square error (RMSE). Grey colours show the HRDPS wind speed without downscaling, blue colours show the HRDPS wind speed combined with WindNinja microscale winds (HRDPS $+\mathrm{WN}$ ) and red colours show the same configuration as HRDPS $+\mathrm{WN}$ including in addition the wind speed reduction on leeward slopes. Stations used for evaluation are classified by increasing TPI (Table 3 ). Their location is shown in Fig. 1.

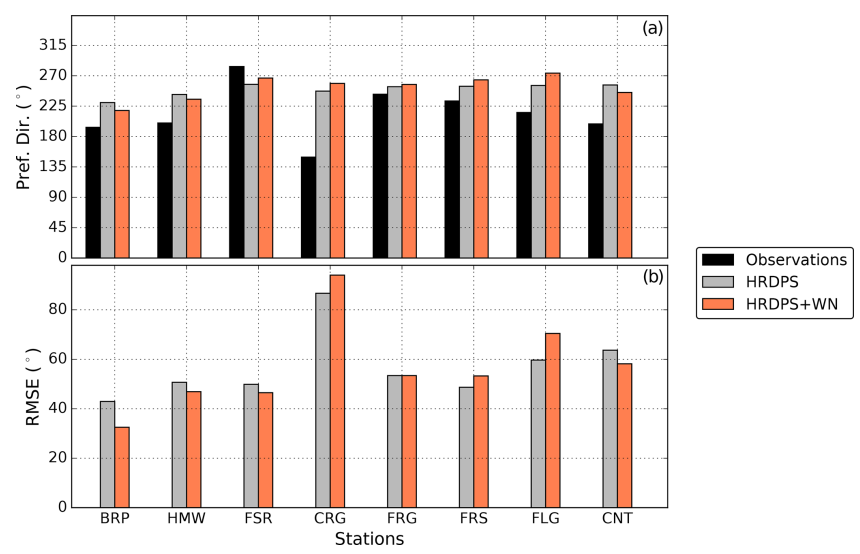

Figure 5. Same as Fig. 4 for wind direction: (a) preferential wind direction and (b) root-mean-square error (RMSE). Error metrics were computed for wind direction only when observed wind speed was larger than $3 \mathrm{~m} \mathrm{~s}^{-1}$. Configuration HRDPS $+\mathrm{WN}+\mathrm{Rc}$ is not shown since the wind direction is unchanged compared to HRDPS $+\mathrm{WN}$.

in Fig. 6c). The reference CHM with lateral redistribution of snow and wind speed reduction in leeward slopes, WndTr Av Rc, brought large improvements (Fig. 6b). Accounting for blowing-snow redistribution reduced snow accumulation on windward slopes and locally increased snow deposition in the upper parts of leeward slopes (purple contours in Fig. 6b). It also led to a large increase in snow accumulation in avalanche deposition areas (red contours in Fig. 6b) that better corresponded with observed features of snow accumulation (Fig. 6a). However, WndTr Av Rc presented an overestimation of snow depth in some of the large valleys of the region (blue contours in Fig. 6) where avalanche deposition seemed to be overestimated.

\subsubsection{Elevation dependency of snow depth}

The agreement between observed and simulated snow depth distributions was examined as a function of elevation for three sub-regions (see Fig. 1) of the Kananaskis domain: Kananaskis North, Kananaskis South and Haig (Figs. 7 and 8). For each sub-region, the median of observed snow depth increased with elevation up to $2400 \mathrm{~m}$ followed by a decrease at the highest elevations (Fig. 7), a relationship reported elsewhere (Grünewald et al., 2014; Kirchner et al., 2014). The same trend was found for the other percentiles shown on the whisker plots of the observed distributions of snow depth (Fig. 7). All CHM simulations overestimated the snow depth below $2100 \mathrm{~m}$ for each sub-region, partly explained by the tendency of HRDPS to overestimate precipitation at valley stations (see stations HMW and UPC in Fig. S1 in the Supplement). The CHM simulation without lateral redistribution of snow (NoWndTr NoAv) did not capture the observed spatial variability within each elevation band (Fig. 7). Instead, simulated average snow depth increased with elevation and diverged with observed decreased snow depth recorded with the ALS survey. Therefore, the experiment NoWndTr NoAv presented an increase in the Wasserstein distance and RMSE with elevation (Fig. 8) associated with a continuous decrease in model performance with increasing elevation. Accounting for gravitational redistribution in CHM (experiment NoWndTr Av; orange boxes in Fig. 7) increased the spatial variability within each elevation band and reduced snow accumulation above $2400 \mathrm{~m}$, especially for the Haig sub-region (Fig. 7c) characterized by steep slopes prone to avalanching (Fig. 1b). The experiment NoWndTr Av led to improved Wasserstein distance at all elevations for each subregion compared to the experiment NoWndTr NoAv (Fig. 8). Snow depth above $2300 \mathrm{~m}$ for all sub-regions was still overestimated, however (Fig. 7). The increase in RMSE below $2400 \mathrm{~m}$ (Fig. 8) suggested that experiment NoWndTr Av did not capture the location of avalanche deposits well.

Including blowing-snow redistribution strongly affected model results. As expected, it increased the spatial variability of simulated snow depth within each elevation band compared to experiments NoWndTr NoAv and NoWndTr Av (Fig. 7). When the wind speed reduction in leeward areas was not simulated (experiment WndTr Av NoRc), CHM underestimated the median snow depth (as well as the first and third quartiles) above $2500 \mathrm{~m}$ compared to observations. This underestimation increased with elevation and was largest for the elevation band $2900-3100 \mathrm{~m}$. Including the recirculation effect when simulating blowing snow (experiment WndTr Av Rc) strongly improved the ability of the model to capture the distribution of snow depth at high elevation (above $2700 \mathrm{~m}$ for Kananaskis North, Fig. 8a; above $2500 \mathrm{~m}$ for Kananaskis South, Fig. 8b; and above $2100 \mathrm{~m}$ for Haig, Fig. 8c). Over- 


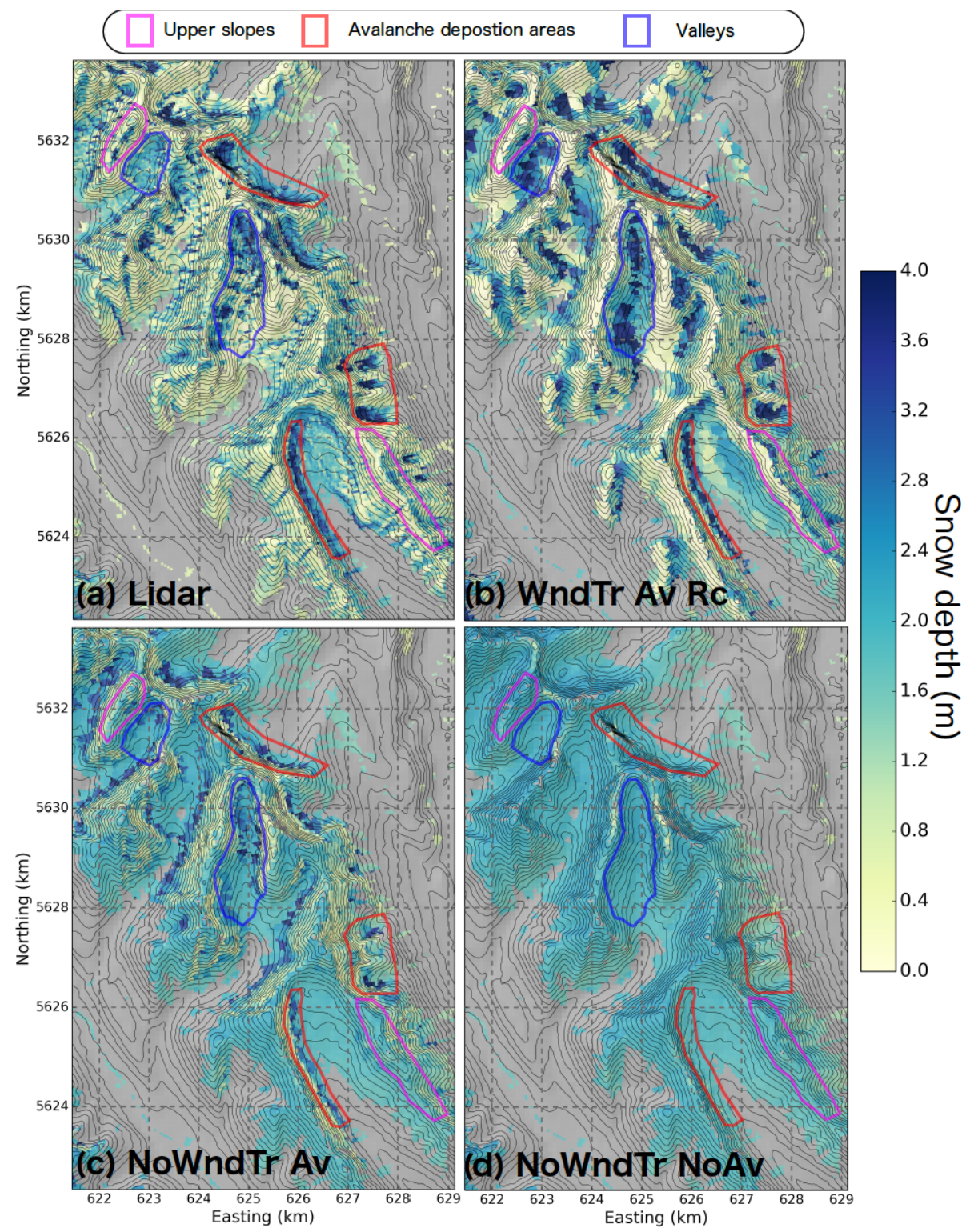

Figure 6. Snow depth on 27 April 2018 (a) measured by ALS and simulated by three CHM configurations: (b) WndTr Av Rc, (c) NoWndTr Av and (d) NoWndTr NoAv (Table 3). Properties of snow depth distribution in areas with coloured contours are discussed in the text. Pixels covered by tall vegetation in the observations and in the simulations are excluded from the comparison and appear in grey. Black isolines correspond to $\Delta \mathrm{z}=50 \mathrm{~m}$, and the location of this region is shown in Fig. $1 \mathrm{~b}$.

all, the experiment WndTr Av Rc captured the observed shape of the elevation-snow depth relation for each subregion (Fig. 7). Below 2300 m, experiments WndTr Av NoRc and WndTr Av Rc overestimated the value of the 95th percentile of the snow depth distribution compared to observations (Fig. 7). These two configurations of CHM also led to a larger Wasserstein distance (between 1900 and $2100 \mathrm{~m}$ ) and larger RMSE (below $2500 \mathrm{~m}$ ) compared to experiments NoWndTr NoAv and NoWndTr Av. These results are consistent with the overestimation of gravitational snow redis- tribution to lower elevation and the erroneous location of avalanche deposits observed in Fig. 6 b.

\subsubsection{Snow distribution around ridges}

The observed and simulated snow depth distributions were compared for the upper slopes of the domain (defined in Sect. 2.3.2), particularly exposed to wind-induced snow transport (Fig. 9). The CHM simulation without lateral redistribution of snow, NoWndTr NoAv, presented a systematic overestimation of snow depth for all slope orientations (Fig. 9a-c) and yielded the worst Wasserstein distance met- 

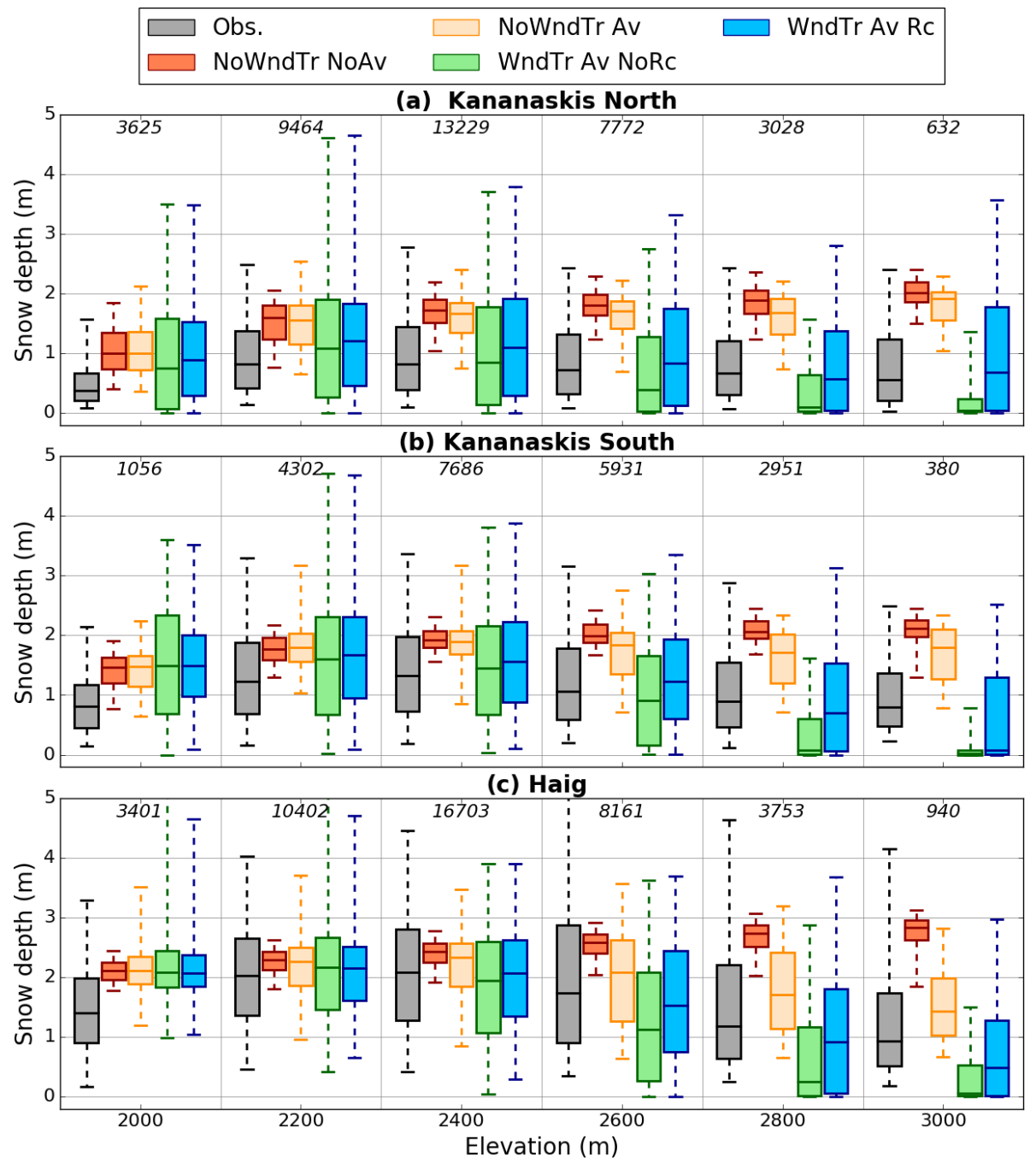

Figure 7. Boxplots showing the distributions of observed and simulated snow depth per $200 \mathrm{~m}$ elevation band for three sub-regions. The location of these sub-regions is shown in Fig. 1b. Results of four CHM experiments are shown. The numbers in italic indicate the number of grid points within each elevation band. The whiskers show the 5th and 95th percentiles and outliers are not plotted.

ric among all simulations (Fig. 9d-f). Including gravitational redistribution reduced the positive bias and the Wasserstein distance. This reduction was not found for some slope orientations, however (W, SW and S orientations for Kananaskis North, Fig. 9a; SW and S orientations for Kananaskis South, Fig. 9b). The moderate values of the slope angle generally found for these orientations were not sufficient to trigger gravitational snow redistribution in SnowSlide. For example, the percentage of slope values larger than $40^{\circ}$ is only $9 \%$ for the SW and S orientations for Kananaskis North, compared to $43 \%$ and $63 \%$ for the $\mathrm{N}$ and $\mathrm{NE}$ orientations for the same region, respectively. Accounting for blowing-snow redistribution without wind speed reduction in leeward areas generated a systematic underestimation of snow depth for all slope orientations and sub-regions (Fig. 9a-c). This negative bias in snow depth indicates that snow erosion on the windward slopes ( $\mathrm{S}$ to NW orientations) was overestimated for experiment WndTr Av NoRc. Thinner-than-observed snow depth on the upper part of the leeward slopes ( $\mathrm{N}$ to SE orientations in Fig. 9a-c) suggests that the windblown snow eroded in excess from the windward slopes was transported by PBSM-3D to the lower part of the leeward slopes due to the absence of wind recirculation in the driving wind field used by experiment WndTr Av NoRc (Fig. 3b). A similar underestimation of snow depth on the windward slopes exists for experiment WndTr Av Rc. Due to the activation of the wind speed reduction in leeward areas, however, this experiment simulated snow deposition in the upper part of these areas. The experiment WndTr Av NoRc led to an overestimation of snow depth on the leeward slopes for Kananaskis North and South ( $\mathrm{N}$ to SE orientations, Fig. 9a, b) and nearly unbiased estimation of snow depth for Haig (NE to SE orientations, Fig. 9c). 
Wasserstein distance

(a) Kananaskis North

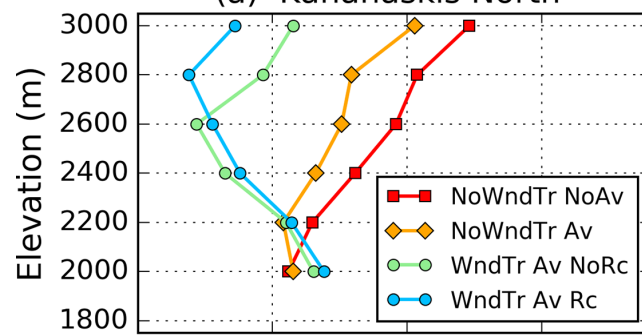

(b) Kananaskis South

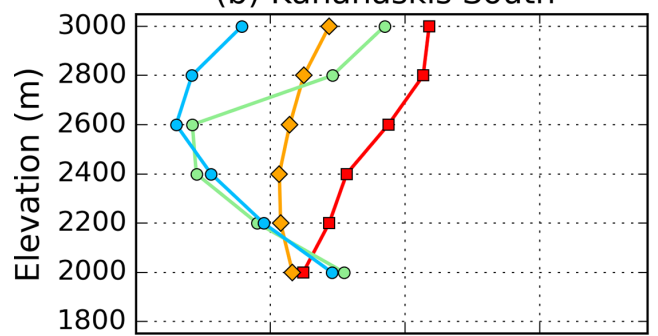

(c) Haig

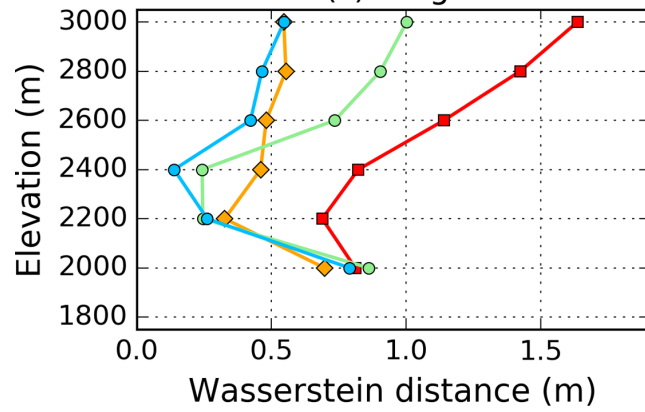

RMSE

(d) Kananaskis North

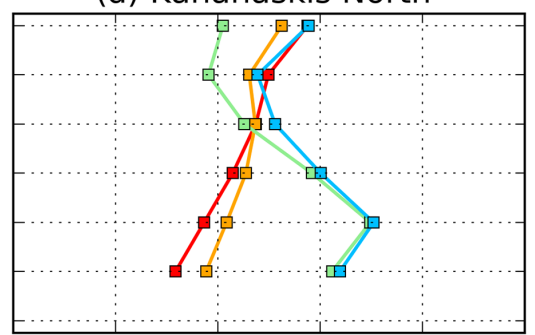

(e) Kananaskis South

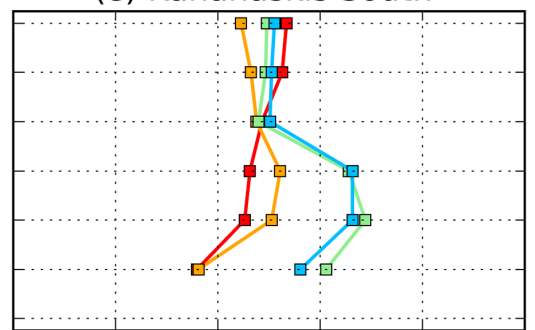

(f) Haig

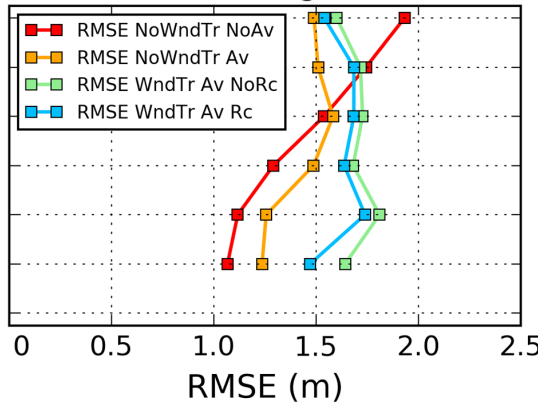

Figure 8. Wasserstein distance and RMSE between observed and simulated snow depth distribution as a function of elevation for four CHM experiments and three sub-regions. The location of these sub-regions is shown in Fig. 1.

Overall, experiment WndTr Av Rc provided the best performance in terms of Wasserstein distance for the windward slopes of all sub-regions (Fig. 9d-f) despite the negative bias in snow depth for these areas. Performance was more mixed for leeward slopes: Haig showed an improvement compared to experiment NoWndTr Av (Fig. 9f), whereas the worst performance was obtained for Kananaskis North (Fig. 9d).

\subsubsection{Snow persistence}

Figure 10 shows the maps of observed snow persistence indexes as well as the indexes derived from two CHM simulations. Observed SP (Fig. 10a) presented similar patterns compared to the observed distribution of snow depth in late April (Fig. 6a), showing that snow persistence patterns are primarily controlled by the patterns of peak snow accumulation (Wayand et al., 2018). Avalanche deposits identified in Fig. 6a corresponded to maximal SP values, whereas low SP values were found near ridge lines, exposed to wind. Overall, the Pearson correlation coefficient between observed snow depth and SP reached $0.69(p<0.001), 0.68(p<0.001)$ and $0.75(p<0.001)$ for Kananaskis North, Kananaskis South and Haig, respectively. Without accounting for lateral snow redistribution (experiment NoWndTr NoAv), CHMsimulation-derived SP values were dependent upon the elevation and slope orientation (Fig. 10c), primarily due to the impact of solar radiation on simulated snow ablation. Without lateral snow redistribution, snow accumulation was spatially uniform (Figs. 6d and 7). Lower values of simulation-derived SP were found in the lower south-facing slopes, whereas steep slopes on northern faces had SP values close to 1.0. The simulation-derived SP was strongly modified with experiment WndTr Av Rc (Fig. 10b), similarly to the effect found for snow depth near peak snow accumulation (Fig. 6b). In this experiment, windward slopes systematically presented low SP values, and maximal SP values close to 1.0 were found at the bottom of slopes due to gravitational redistribution of snow that prevented snow persistence on steep slopes.

Figure 11 shows how accurately the different CHM experiments were able to reproduce the observed SP distributions as a function of elevation. The simulation-derived and observed SP distributions are shown in Fig. S2. Model per- 
Bias (m)

(a) Kananaskis North

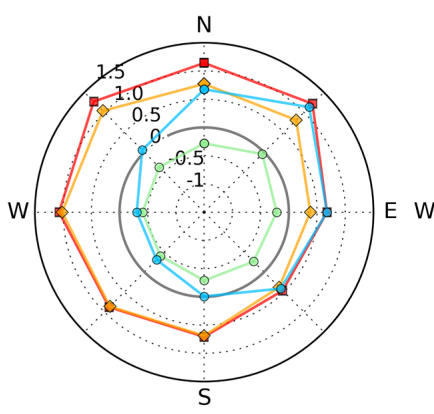

(b) Kananaskis South

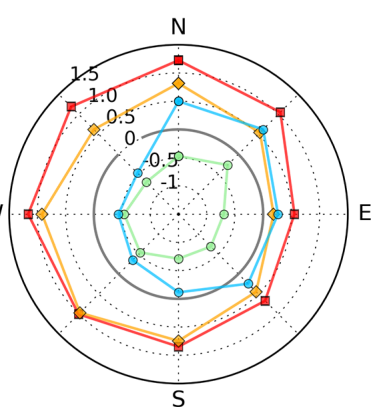

(c) Haig

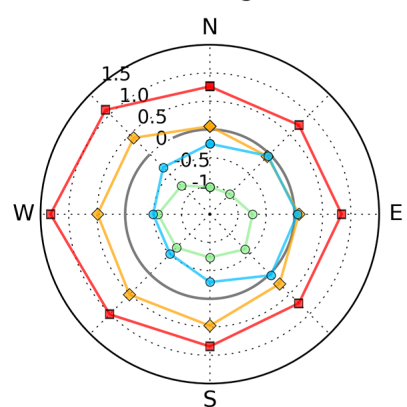

Zero Bias

$\diamond \diamond$ NoWndTr Av

\section{Wasserstein distance $(\mathbf{m})$}

(d) Kananaskis North

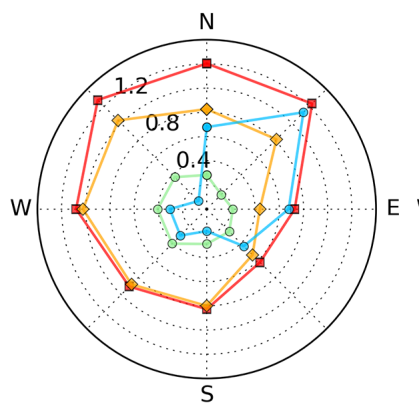

(e) Kananaskis South

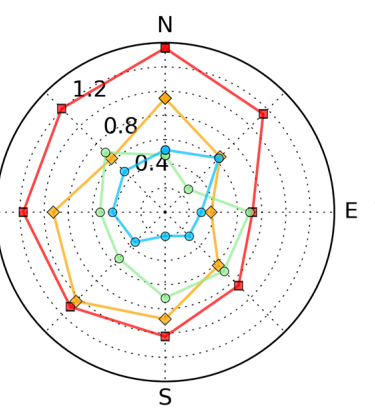

(f) Haig

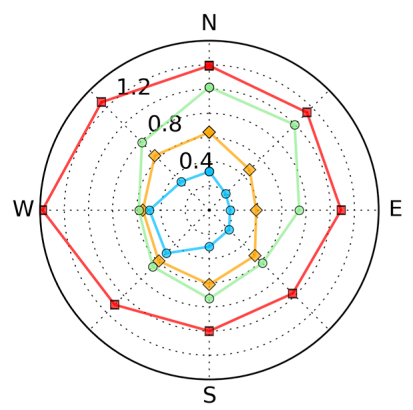

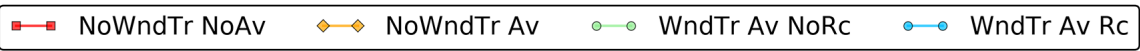

Figure 9. Bias (a-c) and Wasserstein distance (d-f) between observed and simulated snow depth distribution in upper slopes as a function of slope orientation for four CHM experiments and three sub-regions. The location of these sub-regions is shown in Fig. 1. Upper slopes are defined as regions of TPI larger than $150 \mathrm{~m}$ (see Sect. 2.3.2). The thick grey circles on graphs (a-c) indicate a zero bias. Values outside this circle indicate a positive bias, whereas values within this circle indicate a negative bias.

formances for snow persistence were generally in agreement with those for snow depth presented in Fig. 8. Experiments without blowing-snow redistribution (NoWndTr NoAv and NoWndTr Av) overestimated snow persistence at all elevations with a positive bias increasing with elevation for experiment NoWndTr NoAv. Including blowing-snow redistribution in experiments WndTr Av NoRc and WndTr Av Rc significantly decreased snow persistence, mainly above $2300 \mathrm{~m}$. The absence of wind speed reduction in leeward areas (experiment WndTr Av NoRc) led to negative bias of snow persistence above $2700 \mathrm{~m}$ and a decrease in model performances compared to experiment WndTr Av Rc that includes recirculation effects. Below $2500 \mathrm{~m}$, experiments WndTr Av NoRc provided the best performances in terms of bias and Wasserstein distance. Consistent results compared to snow depth were also obtained when considering how observed and simulated SP distributions vary with slope orientation in upper slopes (Fig. 12). For example, the tendency of experiment WndTr Av Rc to overestimate snow accumulation on the leeward slopes of Kananaskis North led to a clear overestimation of snow persistence on these slopes (Fig. 12a) and a degradation of model performance compared to a simulation without blowing-snow redistribution (Fig. 12d).

\section{Discussion}

\subsection{Modelling of mountain snowpack}

This study presents a new high-resolution modelling strategy for mountain snowpack, combining atmospheric forcing from a NWP system at convection-permitting scale with the multi-scale, snowdrift-permitting model CHM. Several CHM configurations were tested to highlight how omitting physical processes influenced the performances of snowpack simulations at snowdrift-permitting scales $(50 \mathrm{~m}$ in this study). Lateral snow redistribution (blowing snow and avalanching) were required to capture natural variations in snow depth and its persistence, a finding that is in accordance with Winstral et al. (2013) and Hanzer et al. (2016). These results differed from those of Revuelto et al. (2018), who showed that a distributed snowpack scheme without lateral snow redistribution can provide accurate estimation of snow 

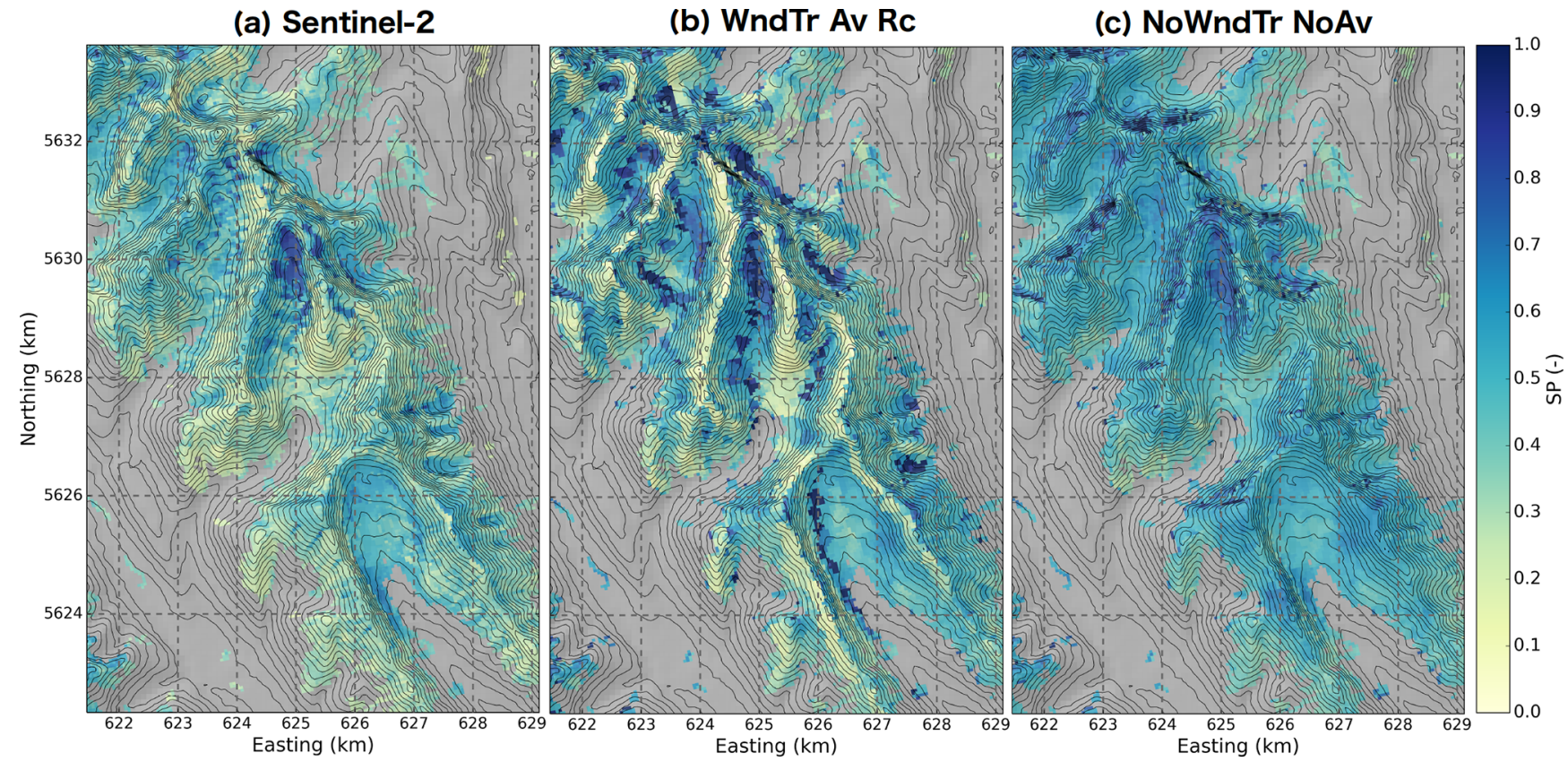

Figure 10. Maps of snow persistence index (SP) (a) derived from Sentinel-2 and simulated by two CHM configurations: (b) WndTr Av Rc, and (c) NoWndTr NoAv (Table 3). Pixels covered by tall vegetation in the observations and in the simulations are excluded from the comparison and appear in grey. Black isolines correspond to $\Delta \mathrm{z}=50 \mathrm{~m}$, and the location of this region is shown in Fig. $1 \mathrm{~b}$.

cover variability. This discrepancy may arise from (i) the resolution of $250 \mathrm{~m}$ used in Revuelto et al. (2018) for which lateral redistribution processes are partially sub-grid and (ii) the absence of ALS data and high-resolution satellite images to evaluate their snowpack simulations. Accounting for gravitational redistribution reduced snow accumulation and persistence in steep slopes in agreement with the findings of Bernhardt and Schulz (2010). However, snow depth and persistence were still overestimated for the upper slopes exposed to wind. The CHM simulation (WndTr Av Rc) that included blowing-snow redistribution and avalanching was required to capture the decrease in snow depth at high elevation (above $2500 \mathrm{~m}$ ); it also improved the elevation-snow depth relationship for all sub-domains of the Kananaskis domain. Similar elevation-snow depth relationships presenting a snow depth maximum below the highest elevations have also been reported for other mountainous regions (Grunewald et al., 2014; Kirchner et al., 2014). Our results suggest that accounting for blowing-snow redistribution and avalanching in distributed snowpack simulations is crucial to accurately simulate the elevation-snow depth relationships in high-mountain terrain.

Results of blowing-snow redistribution simulations in CHM were sensitive to the quality of the driving wind field, in particular the impact of recirculation areas, at the mountain range scale $\left(>100 \mathrm{~km}^{2}\right)$. This observation builds on the similar findings of Mott and Lehning (2010) and Musselman et al. (2015) based on ridge-scale simulations of snow depth. High-resolution wind fields obtained using the mass- conserving version of the diagnostic wind model WindNinja (Forthofer et al., 2014) presented some features of atmospheric flow in alpine terrain (e.g., valley channelling, crest speed-up) but they did not capture the formation of recirculation areas on leeward slopes. This lack of recirculation led to lower-than-observed snow deposition and persistence on leeward slopes. These results highlight the limitations of mass-conserving diagnostic wind models for blowing-snow modelling in alpine terrain. Combining high-resolution wind fields from WindNinja with a terrain-based parameter (Winstral and Marks, 2002) allowed identification of potential areas of flow separation on leeward slopes and improved simulations of the elevation-snow depth relationship and of the snow distribution and persistence around ridges. This simulation was still impacted by an overestimation of snow erosion on windward slopes and subsequent deposition on leeward slopes, likely arising from uncertainties associated with the wind-downscaling method and limitations in CHM parameterizations discussed in Sect. 4.3 and 4.4.

\subsection{Importance of high-resolution distributed evaluation data}

The evaluation of the wind-downscaling methods versus point measurements did not show systematic improvements compared to the original HRDPS wind field, consistent with studies of high-resolution wind modelling in complex terrain (e.g., Horvath et al., 2012; Vionnet et al., 2015). Model results in Sect. 3.1 highlight the challenge of evaluating 
Bias

(a) Kananaskis North

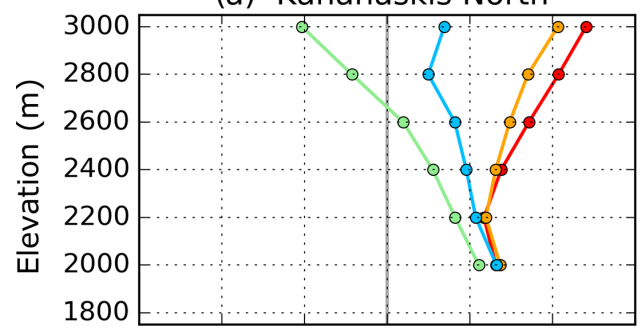

(b) Kananaskis South

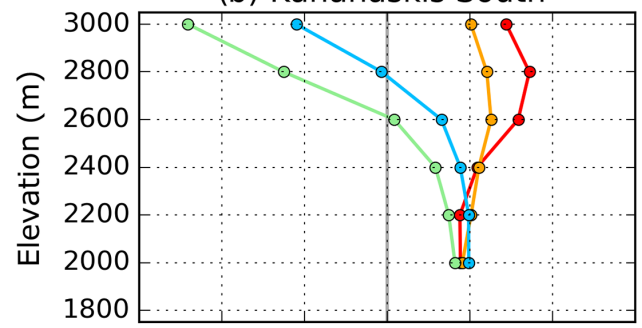

(c) Haig

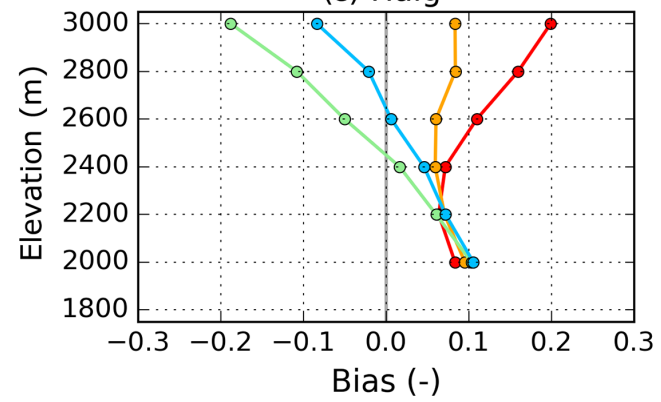

Wasserstein distance

(d) Kananaskis North

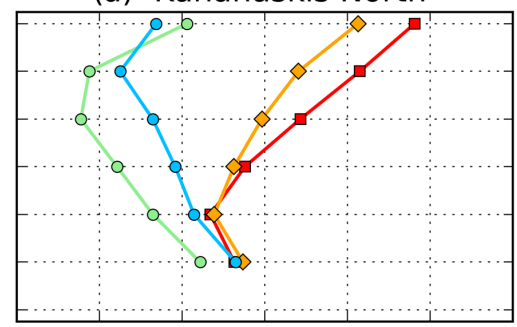

(e) Kananaskis South

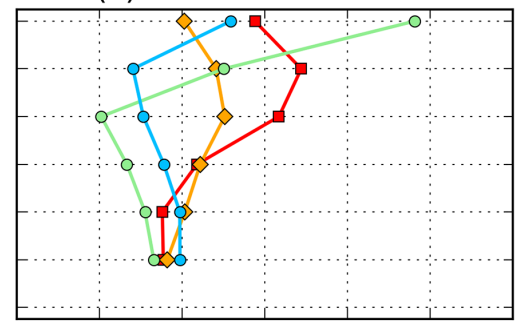

(f) Haig

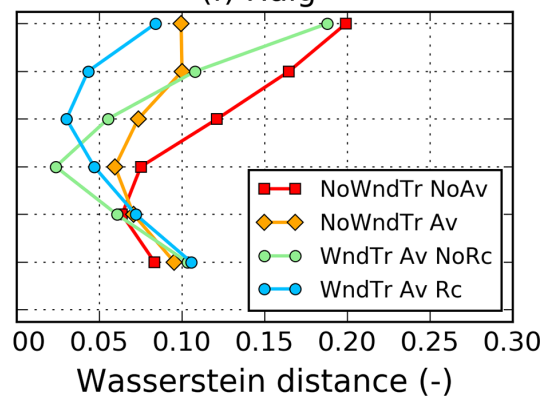

Figure 11. Bias and Wasserstein distance between observed and simulated snow persistence index as a function of elevation for four CHM experiments and three sub-regions. The location of these sub-regions is shown in Fig. 1.

wind simulations at locations near peaks or ridges due to approximation in the location of the stations as previously mentioned in Fiddes and Gruber (2014) and Winstral et al. (2017). On the other hand, differences between the winddownscaling methods were clearly identified and quantified when evaluating the snow simulations using distributed data. ALS snow depth and snow persistence indexes derived from Sentinel-2 allowed for targeted model evaluation in areas of interest such as the upper slopes exposed to wind-induced snow transport. These results confirm the large potential of ALS snow depth data for detailed model evaluation (e.g., Hanzer et al., 2016; Hedrick et al., 2018). In addition, they show that snow persistence indexes derived from freely available Sentinel-2 images (Wayand et al., 2018) can generally support more similar conclusions than those derived from ALS snow depth. This highlights the fact that these indexes can be used to evaluate large-scale snowpack simulations at snowpack-permitting scales in regions that are not covered by lidar. As illustrated by Wayand et al. (2018), the snow persistence index is influenced by variability in both snow accumulation and ablation, so that this index can only be used to evaluate snow redistribution models if variable insolation effects are also simulated. This is the case in the simulations presented in this paper (Sect. 2.2.5).

Two types of metrics were used when using ALS snow depth data for model evaluation: RMSE and Wasserstein distance. RMSE corresponds to a traditional "point-to-point" verification metric. Such a metric may favour homogenous snow cover simulations. Indeed, a snow cover simulation including avalanching may present a degree of realism, but errors in the exact location of the avalanche deposits may increase RMSE compared to a simulation without avalanching due to the double-penalty problem (e.g., Nurmi, 2003). This issue is often encountered when evaluating the ability of high-resolution atmospheric models to simulate localized events such as convective precipitation (e.g., Clark et al., 2016). The Wasserstein distance (Rüschendorf, 1985) was used in this study as a complementary metric to evaluate the agreement between observed and simulated distributions for specific areas (elevation bands or specific slope orientations). This metric may lead to a perfect match even if the observations and the simulations are not co-located, however. This 
Bias (-)

(a) Kananaskis North

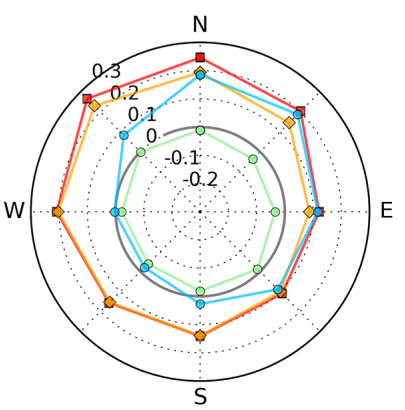

b) Kananaskis South

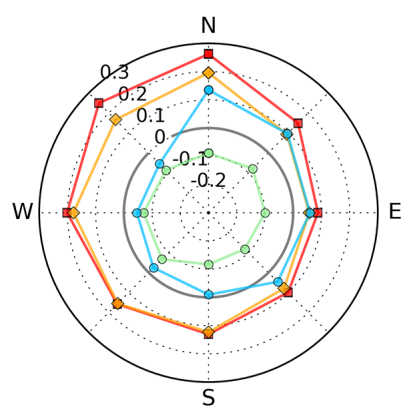

(c) Haig

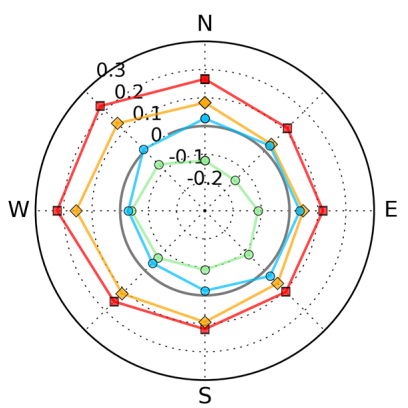

- Zero Bias $\because$ NoWndTr NoAv $\diamond \diamond$ NoWndTr Av $\diamond \cdots$ WndTr Av NoRc $\bullet \multimap$ WndTr Av Rc

Wasserstein distance (-)

(d) Kananaskis North

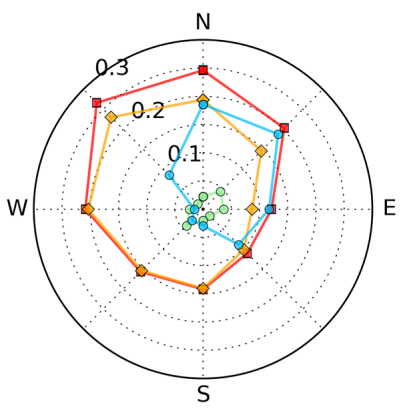

(e) Kananaskis South

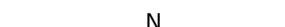

(f) Haig

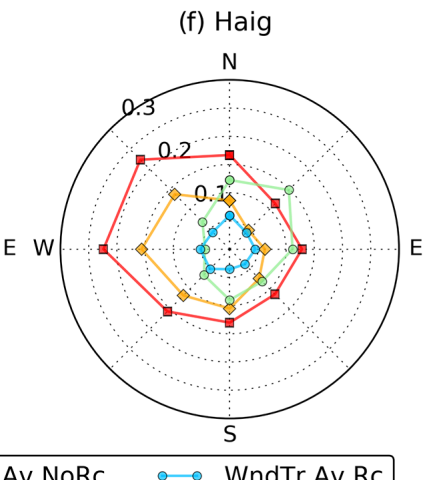

Figure 12. Same as Fig. 9 but for the snow persistence index (SP).

highlights the need to consider several verification metrics with identified strengths and limitations. In the future, more advanced verification methods such as the neighbourhood method developed in the atmospheric community (Ebert et al., 2013) could be considered.

\subsection{Uncertainties in the atmospheric driving data}

This study used a wind-downscaling method inspired by Barcons et al. (2018) and developed for large areas. Part of the uncertainty associated with this method comes from the value of the radius of influence used to compute the transfer functions (Sect. 2.2.4). A value of $1 \mathrm{~km}$ was selected for this study, similar to Barcons et al. (2018) as the resolutions of the mesoscale atmospheric models were similar between the two studies $(2.5 \mathrm{~km}$ in this study and $3 \mathrm{~km}$ in Barcons et al., 2018). Further work is required to adapt this value to the resolution of the mesoscale atmospheric models and to the terrain complexity. Sensitivity tests revealed that the wind field in the upper slopes strongly depends on the value of the radius of influence with a potential large impact on simulated snow redistribution. The accuracy of the wind downscaling was also influenced by the quality of the diagnostic wind model used to generate microscale wind fields. In particular, the mass-conserving version of WindNinja used in this study failed to simulate the formation of recirculation areas on leeward slopes that are one of the main features of atmospheric flow in alpine terrain (Raderschall et al., 2008; Gerber et al., 2017). The practical method relying on the Winstral parameter (Winstral and Marks, 2002) proposed to overcome this limitation is affected by strong assumptions on the value of the critical angle for flow separation (Wood, 1995). Gerber et al. (2017) showed that atmospheric stability affects the value of this angle and the development of lee-side recirculation. A constant value of 0.25 is used for the transfer function in recirculation zones. This value falls within the range of values reported in Fig. 10 of Menke et al. (2019) for the ratio, $R$, between the maximum wind speed in recirculation flow and the inflow wind speed at the crest. Menke et al. (2019) found that $R$ tends to decrease with increasing stability in a stable atmosphere and it presents values lower than 0.3 for inflow wind speed greater than $12 \mathrm{~m} \mathrm{~s}^{-1}$. This suggests that a dynamic value based on atmospheric stability could be used for the transfer function in recirculation zones. In addition, the wind direction is not modified in these areas, contrary to simulations resulting from CFD models or atmospheric models in LES mode (Gauer, 1998; Mott and Lehning, 2010; Vionnet et al., 2017). Improvements in the wind downscaling 
could be achieved using such models to generate the library of wind fields, as proposed by Barcons et al. (2018). Different conditions of atmospheric stability could also be considered (e.g., Gerber et al., 2017) as well as different input wind speeds that affect significant flow features such as flow separation. Final selection of the wind-downscaling strategy will ultimately be a trade-off between model complexity, accuracy and computational costs and will vary as a function of model applications.

All the atmospheric driving data for CHM were obtained from the HRDPS, the Canadian NWP system using GEM at $2.5 \mathrm{~km}$ (Milbrandt et al., 2016). It consisted of successive short-range forecasts combined to generate a continuous atmospheric forcing. Such an approach has been used previously to generate atmospheric forcing for snowpack models in mountainous terrain (Horton and Jamieson, 2016; Quéno et al., 2016; Vionnet et al., 2016; Luijting et al., 2018). Error in the snowpack variables can grow with time due to errors in the successive forecasts, especially those due to precipitation biases (e.g., Vionnet et al., 2019). Errors in the longwave and shortwave radiative input can also significantly affect snowpack simulations (Lapo et al., 2015; Quéno et al., 2020). The downscaling techniques used to adapt the HRDPS forcing to the CHM mesh likewise contribute to the uncertainty in the quality of the meteorological input. Monthly fixed altitudinal gradients were used to adjust the near-surface temperature and humidity forcing; this method might be further improved using upper-air HRDPS temperatures and humidity fields (e.g., Jarosch et al., 2012; Fiddes and Gruber, 2014). Contributions from the surrounding topography to longwave irradiance were also neglected, despite its impact on the snowpack energy balance on inclined slopes (Pluss and Ohmura, 1997). Ensemble simulations based on ensemble meteorological forcing (e.g., Vernay et al., 2015) and ensemble downscaling methods (Marsh et al., 2020a) could be used to investigate the impact of these sources of uncertainties.

\subsection{Limitations in the physical parameterizations in CHM}

The model evaluation for the upper slopes exposed to wind showed that CHM simulations including blowing snow tend to overestimate snow redistribution across slopes subject to wind erosion and deposition. These results were obtained for a CHM mesh with a typical area of $50 \mathrm{~m} \times 50 \mathrm{~m}$ near the crest lines. Mott and Lehning (2010) found a similar overestimation of snow redistribution in simulations of the snow cover evolution for a crest of the Swiss Alps using the Alpine 3D model (Lehning et al., 2008) running at $50 \mathrm{~m}$ grid spacing. They showed that increasing the model resolution finer than $10 \mathrm{~m}$ increased snow accumulation on the windward side due a more accurate representation of small-scale terrain features trapping snow on the windward side. These results suggest that the absence of any subgrid topography effects on snow transport in CHM can partially explain the overestimation of snow redistribution from windward slopes to leeward slopes and subsequent avalanching. In addition, CHM uses the formulation for the threshold friction velocity for snow transport of $\mathrm{Li}$ and Pomeroy (1997) that only depends on snow presence and air temperature. Though based on a large multi-year observational dataset, such parameterization is empirical and does not also account for the effect of snow fragmentation during blowing-snow events (Comola et al., 2017), which may lead to an underestimation of the threshold friction velocity and an overestimation of blowing-snow occurrence in alpine terrain (Vionnet et al., 2013). CHM may benefit from the inclusion of a more physically based snow transport routine in the future. Finally, CHM uses a thickness of $5 \mathrm{~m}$ for the suspension layer (Marsh et al., 2020a). This is sufficient to capture most of the mass transported in alpine terrain over slopes exposed to wind with limited fetches (Pomeroy et al., 1993; Naaim Bouvet et al., 2010) but it cannot simulate the formation of snow plumes at crest lines. Mass loss due to the advection of blown snow particles to atmospheric layers and subsequent sublimation are likely underestimated by CHM. Such a limitation is also found for more advanced blowing-snow schemes (see for example Fig. 6 of Groot Zwaaftink et al., 2011, and Fig. 8.6 of Vionnet, 2012).

Gravitational snow redistribution is simulated in CHM with the SnowSlide scheme (Bernard and Schulz, 2010). Model results showed that $\mathrm{CHM}$ can reproduce the formation of snow accumulations due to avalanching that visibly correspond with the observations. However, the increase in RMSE for snow depth at low elevation for all simulations including avalanching suggests that CHM does not effectively capture the true location of these deposits. SnowSlide relies on a maximum holding capacity of snow that only depends on the slope angle and does not consider the small-scale terrain roughness, limiting the ability of the scheme to reproduce snow accumulation for steep faces (Sommer et al., 2015). In addition, the exact location of avalanche deposits is influenced by avalanche dynamics (Pudasaini and Hutter, 2007), which are not reproduced in SnowSlide. CHM also does not represent snowfall enhancement due to interactions between the flow field and the local cloud formation as well as the preferential deposition of snowfall resulting from pure particle flow interaction (Lehning et al., 2008; Vionnet et al., 2017; Mott et al., 2018). Gerber et al. (2019) suggested that, when combined, these two effects can increase snow accumulation on the leeward side of mountain ridges by $26 \%-$ $28 \%$. In the current version of CHM, wind-induced snow transport is the only process responsible for additional snow deposition on leeward slopes. The parameterization of Dadic et al. (2010) could be tested in CHM but would require an estimation of the vertical wind speed that could be provided by WindNinja. A study is in progress in the Canadian Rockies to better assess the impact of terrain-flow-precipitation interactions on snow accumulation in the region. Finally, uncertainties associated with the Snobal snowpack scheme 
were not quantified in this study. In particular, errors in simulated snow density can affect the comparison between observed and simulated snow depth (Raleigh and Small, 2017; Lv and Pomeroy, 2020), despite the use of an improved snow density algorithm for Snobal (Hedrick et al., 2018). Inaccurate estimations of the ground heat flux may also affect the simulation of the snow cover duration (Slater et al., 2017). Pritchard et al. (2020) showed how multi-physics ensemble snow modelling can be applied to assess uncertainties on distributed snowpack simulations and a similar framework could be applied to CHM, including uncertainties in PBSM3D and SnowSlide.

\section{Conclusions}

This study presents a new multi-scale modelling strategy for mountain snowpacks over large regions. It combines (i) atmospheric forcing from the Canadian GEM NWP system at a convective-permitting scale (Milbrandt et al., 2016), (ii) a meteorological downscaling module including a winddownscaling strategy relying on the diagnostic wind model WindNinja (Forthofer et al., 2014) and (iii) the multi-scale snowdrift-permitting model CHM (Marsh et al., 2020a, b). This system was used to simulate the snowpack evolution for an entire snow season over a domain of $958 \mathrm{~km}^{2}$ in the Kananaskis Valley of the Canadian Rockies. Wind simulations were evaluated using data from automatic stations in the domain. The distributed evaluation data for the snowpack simulations consisted of maps of snow depth derived from airborne lidar and snow persistence indexes derived from optical satellite imagery. Several configurations of CHM were tested to assess the effect of the wind field downscaling and the impact of process representation on snowpack simulations at snowdrift-permitting scales.

The main conclusions of this study are as follows.

- Pre-computed wind fields at $50 \mathrm{~m}$ grid spacing with the WindNinja model can be combined efficiently with output of the Canadian NWP system at $2.5 \mathrm{~km}$ grid spacing to produce hourly driving wind fields including smallscale topographic features. The mass-conserving version of WindNinja used in this study cannot reproduce lee-side flow recirculation, however. The Winstral terrain parameter, $S x$, provides a solution to identify potential recirculation areas and accordingly adjust the wind field downscaled with WindNinja.

- Snowpack simulation without lateral snow redistribution (blowing-snow and gravitational snow redistribution) cannot capture the spatial variability of snow cover in alpine terrain and overestimates snow depth and snow cover duration at high elevations. Including gravitational redistribution improved model results and reduced snow depth at high elevations. Snow depth and snow cover duration were still overestimated around ridge lines exposed to winds.

- Snowpack simulation including blowing-snow and gravitational snow redistribution provided the best estimates of the shape of the elevation-snow depth relation across the Kananaskis region and reproduced the decrease in mean snow depth found at high elevation. These results were obtained for a CHM experiment driven by a wind field including the wind speed reduction in leeward areas. Removing this reduction led to a systematic underestimation of snow depth around ridges, partially due to an underestimation of snow deposition on leeward slopes. These results highlight that wind fields without lee-side slowdown are not sufficient to simulate snow redistribution in mountainous terrain.

- Snowpack simulations including blowing-snow and gravitational snow redistribution overestimated snow redistribution from windward to leeward slopes and subsequent avalanching. This is potentially due to the absence of subgrid topographic effects in the driving wind field and in the snow transport equations in CHM.

- High-resolution snow persistence indexes derived from Sentinel-2 present a strong potential for the detailed evaluation of distributed snowpack models, in particular in regions where airborne lidar snow depth data are not available. These indices can be used for model evaluation targeting specific areas (e.g., ridge lines exposed to intense wind-induced snow redistribution, avalanche deposition areas).

The results of this study demonstrate that $\mathrm{CHM}$ at a snowdrift-permitting scale constitutes a promising tool for large-scale modelling of mountain snowpack. Future work will combine (i) improvements in the physical parameterizations in CHM and in the driving wind fields, (ii) largescale simulations across the western Canadian Cordillera, and (iii) improvements of CHM simulations with assimilation of high-resolution observations such as ALS snow depth or Sentinel-2 snow cover.

Code availability. The open-source CHM model code (Marsh et al., 2020b, https://doi.org/10.5194/gmd-13-225-2020) is available at https://github.com/Chrismarsh/CHM (last access: 29 January 2021). The mesher algorithm (Marsh et al., 2018, https://doi.org/10.1016/j.cageo.2018.06.009) is available at https: //github.com/Chrismarsh/mesher (last access: 29 January 2021). The high-resolution wind library has been generated using the WindNinja diagnostic wind model (Forthofer et al., 2014, https://doi.org/10.1071/WF12089; https://weather.firelab.org/ windninja/, last access: 29 January 2021) and the Windmapper tool (https://github.com/Chrismarsh/Windmapper, last access: 29 January 2021, Marsh and Vionnet, 2021). The Sentinel-2 snow cover maps were generated from level-1C images using the free software 
MAJA (https://logiciels.cnes.fr/en/content/maja, last access: 29 January 2021, CNES, 2021) and the open-source software LIS (https:// gitlab.orfeo-toolbox.org/remote_modules/let-it-snow/, last access: 29 January 2021, Gascoin et al., 2019, https://doi.org/10.5194/essd11-493-2019).

Data availability. CRHO meteorological and snow observations are available through the web portal http://giws.usask.ca/meta/ (last access: 29 January 2021, GIWS, 2021). HRDPS forecasts are distributed on the Canadian Surface Prediction Archive (CaSPAr, https://caspar-data.ca/, last access: 29 January 2021, Mai et al., 2020, https://doi.org/10.1175/BAMS-D-19-0143.1). Sentinel-2 level 1C data were obtained from the Plateforme d'Exploitation des Produits Sentinel (https://peps.cnes.fr, last access: 29 January 2021, CNES, 2021). Final snow cover maps over the Kananaskis Valley are available on Zenodo (Gascoin, 2020, https://doi.org/10.5281/zenodo.3834623). The HRDPS forcing file and the ALS data used in this study are available on request to the authors.

Supplement. The supplement related to this article is available online at: https://doi.org/10.5194/tc-15-743-2021-supplement.

Author contributions. VV, CM, BM and JP designed the study and the modelling strategy. VV and $\mathrm{CM}$ developed the winddownscaling module in CHM. VV was responsible for the analysis of the results and the preparation of the manuscript. BM, JS and KM processed and provided the airborne lidar snow depth data. SG processed and provided the Sentinel 2 snow cover images. NW provided a pre- and post-processing toolkit for CHM. All authors contributed to the preparation of the manuscript.

Competing interests. The authors declare that they have no conflict of interest.

Acknowledgements. Martyn Clark (USask) and Barbara Casati (ECCC) are thanked for their helpful scientific discussions. Special thanks are due to Logan Fang (USask) and Greg Galloway (USask) for providing quality-controlled snow and meteorological data. Simon Gascoin acknowledges the Centre National d'Etudes Spatiales (CNES) for granting him access to its high-performance computer. We thank Rebecca Mott and Tobias Sauter for their careful reading and useful comments, which improved the manuscript.

Financial support. This research has been supported by the Canada First Research Excellence Fund (Global Water Futures), the Natural Sciences and Engineering Research Council of Canada (Discovery Grants), Alberta Innovates (Water Innovation Program), Canada Research Chairs (CRC in Water Resources and Climate Change, $\mathrm{CRC}$ in Glacier Change), and the Canadian Foundation for Innovation and Tula Foundation.
Review statement. This paper was edited by Jürg Schweizer and reviewed by Rebecca Mott and Tobias Sauter.

\section{References}

Baba, M. W., Gascoin, S., and Hanich, L.: Assimilation of Sentinel2 data into a snowpack model in the High Atlas of Morocco. Remote Sens., 10, 1982, https://doi.org/10.3390/rs10121982, 2018.

Barcons, J., Avila, M., and Folch, A.: A wind field downscaling strategy based on domain segmentation and transfer functions, Wind Energy, 21, 409-425, https://doi.org/10.1002/we.2169, 2018.

Bernhardt, M. and Schulz, K.: SnowSlide: A simple routine for calculating gravitational snow transport. Geophys. Res. Lett., 37, L11502, https://doi.org/10.1029/2010GL043086, 2010.

Bernhardt, M., Liston, G. E., Strasser, U., Zängl, G., and Schulz, K.: High resolution modelling of snow transport in complex terrain using downscaled MM5 wind fields, The Cryosphere, 4, 99-113, https://doi.org/10.5194/tc-4-99-2010, 2010.

Brauchli, T., Trujillo, E., Huwald, H., and Lehning, M.: Influence of slope-scale snowmelt on catchment response simulated with the Alpine3D model, Water Resour. Res., 53, 10723-10739, https://doi.org/10.1002/2017WR021278, 2017.

Clark, M. P., Hendrikx, J., Slater, A. G., Kavetski, D., Anderson, B., Cullen, N. J., Kerr T., Hreinsson E. O., and Woods, R. A.: Representing spatial variability of snow water equivalent in hydrologic and land-surface models: A review, Water Resour. Res., 47, W07539, https://doi.org/10.1029/2011WR010745, 2011.

Clark, P., Roberts, N., Lean, H., Ballard, S. P., and CharltonPerez, C.: Convection-permitting models: a step-change in rainfall forecasting, Meteorol. Appl., 23, 165-181, https://doi.org/10.1002/met.1538, 2016.

CNES (Centre National d'Études Spatiales): MAJA (MACCSATCOR Joint Algorithm), available at: https://logiciels.cnes.fr/ en/content/maja, last access: 29 January 2021.

Comola, F., Kok, J. F., Gaume, J., Paterna, E., and Lehning, M.: Fragmentation of wind-blown snow crystals. Geophys. Res. Lett., 44, 4195-4203, https://doi.org/10.1002/2017GL073039, 2017.

Dadic, R., Mott, R., Lehning, M., and Burlando, P.: Parameterization for wind-induced preferential deposition of snow, Hydrol. Process., 24, 1994-2006, https://doi.org/10.1002/hyp.7776, 2010.

Davies, T. D., Palutikof, J. P., Guo, X., Berkofsky, L., and Halliday, J.: Development and testing of a two-dimensional downslope wind model, Bound.-Lay. Meteorol., 73, 279-297, https://doi.org/10.1007/BF00711260, 1995.

Dozier, J.: Spectral signature of alpine snow cover from the Landsat Thematic Mapper, Remote Sens. Environ., 28, 9-22, https://doi.org/10.1016/0034-4257(89)90101-6, 1989.

Dozier, J. and Frew, J.: Rapid calculation of terrain parameters for radiation modeling from digital elevation data, IEEE T. Geosci. Remote, 28, 963-969, https://doi.org/10.1109/36.58986, 1990.

Drusch, M., Bello, U. D., Carlier, S., Colin, O., Fernandez, V., Gascon, F., Hoersch, B., Isola, C., Laberinti, P., Martimort, P., Meygret, A., Spoto, F., Sy, O., Marchese, F., and Bargellini, P.: Sentinel-2: ESA's Optical High-Resolution Mis- 
sion for GMES Operational Services, Remote Sens. Environ., 120, 25-36, https://doi.org/10.1016/j.rse.2011.11.026, 2012.

Dumont, M., Sirguey, P., Arnaud, Y., and Six, D.: Monitoring spatial and temporal variations of surface albedo on Saint Sorlin Glacier (French Alps) using terrestrial photography, The Cryosphere, 5, 759-771, https://doi.org/10.5194/tc-5-759-2011, 2011.

Durand, M. and Margulis, S. A.: Effects of uncertainty magnitude and accuracy on assimilation of multiscale measurements for snowpack characterization, J. Geophys. Res., 113, D02105, https://doi.org/10.1029/2007JD008662, 2008.

Durand, Y., Guyomarc'h, G., Mérindol, L., and Corripio, J. G.: Improvement of a numerical snow drift model and field validation, Cold Reg. Sci. Technol., 43, 93-103, https://doi.org/10.1016/j.coldregions.2005.05.008, 2005.

Earth Resources Observation And Science (EROS) Center: Shuttle Radar Topography Mission (SRTM) Non-Void Filled [Data set], U.S. Geological Survey, https://doi.org/10.5066/F7K072R7, 2017.

Ebert, E., Wilson, L., Weigel, A., Mittermaier, M., Nurmi, P., Gill, P., Gober, M., Joslyn, S., Brown, B., Fowler, T., and Watkins, A.: Progress and challenges in forecast verification, Meteorol. Appl., 20, 130-139, https://doi.org/10.1002/met.1392, 2013.

Ellis, C. R., Pomeroy, J. W., Brown, T., and MacDonald, J.: Simulation of snow accumulation and melt in needleleaf forest environments, Hydrol. Earth Syst. Sci., 14, 925-940, https://doi.org/10.5194/hess-14-925-2010, 2010.

Essery, R., Li, L., and Pomeroy, J. W.: A distributed model of blowing snow over complex terrain, Hydrol. Process., 13, 2423-2438, https://doi.org/10.1002/(SICI)10991085(199910)13:14/15<2423::AID-HYP853>3.0.CO;2-U, 1999.

Fang, X., Pomeroy, J. W., DeBeer, C. M., Harder, P., and Siemens, E.: Hydrometeorological data from Marmot Creek Research Basin, Canadian Rockies, Earth Syst. Sci. Data, 11, 455-471, https://doi.org/10.5194/essd-11-455-2019, 2019.

Fang, X. and Pomeroy, J. W.: Diagnosis of future changes in hydrology for a Canadian Rockies headwater basin, Hydrol. Earth Syst. Sci., 24, 2731-2754, https://doi.org/10.5194/hess-24-27312020, 2020.

Fiddes, J. and Gruber, S.: TopoSCALE v.1.0: downscaling gridded climate data in complex terrain, Geosci. Model Dev., 7, 387-405, https://doi.org/10.5194/gmd-7-387-2014, 2014.

Forthofer, J. M., Butler, B. W., and Wagenbrenner, N. S.: A comparison of three approaches for simulating fine-scale surface winds in support of wildland fire management. Part I. Model formulation and comparison against measurements, International J. Wildland Fire, 23, 969-981, https://doi.org/10.1071/WF12089, 2014 (data available at: https://weather.firelab.org/windninja/, last access: 29 January 2021).

Freudiger, D., Kohn, I., Seibert, J., Stahl, K., and Weiler, M.: Snow redistribution for the hydrological modeling of alpine catchments, Wires Water, 4, e1232, https://doi.org/10.1002/wat2.1232, 2017.

Garen, D. C. and Marks, D.: Spatially distributed energy balance snowmelt modelling in a mountainous river basin: estimation of meteorological inputs and verification of model results, J. Hydrol., 315, 126-153, https://doi.org/10.1016/j.jhydrol.2005.03.026, 2005.
Garvelmann, J., Pohl, S., and Weiler, M.: Spatio-temporal controls of snowmelt and runoff generation during rain-on-snow events in a mid-latitude mountain catchment, Hydrol. Process., 29, 36493664, https://doi.org/10.1002/hyp.10460, 2015.

Gascoin, S.: Time series of snow cover area products over the Kananaskis Country, Data set, Zenodo, https://doi.org/10.5281/zenodo.3834623, 2020.

Gascoin, S., Lhermitte, S., Kinnard, C., Bortels, K., and Liston, G. E.: Wind effects on snow cover in PascuaLama, Dry Andes of Chile, Adv. Water Resour., 55, 25-39, https://doi.org/10.1016/j.advwatres.2012.11.013, 2013.

Gascoin, S., Grizonnet, M., Bouchet, M., Salgues, G., and Hagolle, O.: Theia Snow collection: high-resolution operational snow cover maps from Sentinel-2 and Landsat-8 data, Earth Syst. Sci. Data, 11, 493-514, https://doi.org/10.5194/essd-11-493-2019, 2019 (data available at: https://gitlab.orfeo-toolbox.org/remote_ modules/let-it-snow/, last access: 29 January 2021).

Gauer, P.: Blowing and drifting snow in Alpine terrain: numerical simulation and related field measurements, Ann. Glaciol., 26, 174-178, https://doi.org/10.3189/1998AoG26-1-174-178, 1998.

GDAL/OGR contributors: GDAL/OGR Geospatial Data Abstraction software Library, Open Source Geospatial Foundation, available at: https://gdal.org (last access: 29 January 2021), 2020.

Gerber, F., Lehning, M., Hoch, S. W., and Mott, R.: A closeridge small-scale atmospheric flow field and its influence on snow accumulation, J. Geophys. Res.-Atmos., 122, 7737-7754, https://doi.org/10.1002/2016JD026258, 2017.

Gerber, F., Mott, R., and Lehning, M.: The importance of nearsurface winter precipitation processes in complex alpine terrain, J. Hydrometeorol., 20, 177-196, https://doi.org/10.1175/JHMD-18-0055.1, 2019.

GIWS (Global Institute for Water Security): Canadian Rockies Hydrological Observatory (CRHO) meteorological and snow observations, University of Saskatchewan (USask), available at: http://giws.usask.ca/meta/, last access: 29 January 2021.

Groot Zwaaftink, C. D., Löwe, H., Mott, R., Bavay, M., and Lehning, M.: Drifting snow sublimation: A high-resolution 3-D model with temperature and moisture feedbacks, J. Geophys. Res.Atmos., 116, D16107, https://doi.org/10.1029/2011JD015754, 2011.

Groot Zwaaftink, C. D., Mott, R., and Lehning, M.: Seasonal simulation of drifting snow sublimation in Alpine terrain, Water Resour. Res., 49, 1581-1590, https://doi.org/10.1002/wrcr.20137, 2013.

Grünewald, T., Bühler, Y., and Lehning, M.: Elevation dependency of mountain snow depth, The Cryosphere, 8, 2381-2394, https://doi.org/10.5194/tc-8-2381-2014, 2014.

Hagolle, O., Huc, M., Desjardins, C., Auer, S., and Richter, R.: MAJA Algorithm Theoretical Basis Document, Zenodo, https://doi.org/10.5281/zenodo.1209633, 2017.

Hansen, M. C., Potapov, P. V., Moore, R., Hancher, M., Turubanova, S. A. A., Tyukavina, A., and Kommareddy, A.: High-resolution global maps of 21st-century forest cover change, Science, 342, 850-853, https://doi.org/10.1126/science.1244693, 2013.

Hanzer, F., Helfricht, K., Marke, T., and Strasser, U.: Multilevel spatiotemporal validation of snow/ice mass balance and runoff modeling in glacierized catchments, The Cryosphere, 10, 1859-1881, https://doi.org/10.5194/tc-10-1859-2016, 2016. 
Hanzer, F., Förster, K., Nemec, J., and Strasser, U.: Projected cryospheric and hydrological impacts of 21 st century climate change in the Ötztal Alps (Austria) simulated using a physically based approach, Hydrol. Earth Syst. Sci., 22, 1593-1614, 10.5194/hess-22-1593-2018, 2018.

Harder, P. and Pomeroy, J. W.: Estimating precipitation phase using a psychrometric energy balance method, Hydrol. Process., 27, 1901-1914, https://doi.org/10.1002/hyp.9799, 2013.

Harder, P., Schirmer, M., Pomeroy, J., and Helgason, W.: Accuracy of snow depth estimation in mountain and prairie environments by an unmanned aerial vehicle, The Cryosphere, 10, 2559-2571, https://doi.org/10.5194/tc-10-2559-2016, 2016.

Harder, P., Pomeroy, J. W., and Helgason, W.: Local-scale advection of sensible and latent heat during snowmelt, Geophys. Res. Lett., 44, 9769-9777, https://doi.org/10.1002/2017GL074394, 2017.

Havens, S., Marks, D., FitzGerald, K., Masarik, M., Flores, A. N., Kormos, P., and Hedrick, A.: Approximating Input Data to a Snowmelt Model Using Weather Research and Forecasting Model Outputs in Lieu of Meteorological Measurements, J. Hydrometeorol., 20, 847-862, https://doi.org/10.1175/JHM-D-180146.1, 2019.

He, S. and Ohara, N.: Modeling Subgrid Variability of Snow Depth Using the Fokker-Planck Equation Approach, Water Resour. Res., 55, 3137-3155, https://doi.org/10.1029/2017WR022017, 2019.

Hedrick, A. R., Marks, D., Havens, S., Robertson, M., Johnson, M., Sandusky, M., Marschall H.-P., Kormos, P. R., Bormann, K. J., and Painter, T. H.: Direct insertion of NASA Airborne Snow Observatory-derived snow depth time series into the iSnobal energy balance snow model, Water Resour. Res., 54, 8045-8063, https://doi.org/10.1029/2018WR023190, 2018.

Hedstrom, N. R. and Pomeroy, J. W.: Measurements and modelling of snow interception in the boreal forest, Hydrol. Process., 12, 1611-1625, https://doi.org/10.1002/(SICI)10991085(199808/09)12:10/11<1611::AID-HYP684>3.0.CO;2-4, 1998.

Helbig, N. and van Herwijnen, A.: Subgrid parameterization for snow depth over mountainous terrain from flat field snow depth, Water Resour. Res., 53, 1444-1456, https://doi.org/10.1002/2016WR019872, 2017.

Horvath, K., Koracin, D., Vellore, R., Jiang, J., and Belu, R.: Sub-kilometer dynamical downscaling of nearsurface winds in complex terrain using WRF and MM5 mesoscale models, J. Geophys. Res.-Atmos., 117, D11111, https://doi.org/10.1029/2012JD017432, 2012.

Horton, S. and Jamieson, B.: Modelling hazardous surface hoar layers across western Canada with a coupled weather and snow cover model, Cold Reg. Sci. Technol., 128, 22-31, https://doi.org/10.1016/j.coldregions.2016.05.002, 2016.

Houze Jr., R. A.: Orographic effects on precipitating clouds, Rev. Geophys., 50, RG1001, https://doi.org/10.1029/2011RG000365, 2012.

Jarosch, A. H., Anslow, F. S., and Clarke, G. K.: High-resolution precipitation and temperature downscaling for glacier models, Clim. Dynam., 38, 391-409, https://doi.org/10.1007/s00382010-0949-1, 2012.

Kienzle, S. W.: Effects of area under-estimations of sloped mountain terrain on simulated hydrological behaviour: a case study using the ACRU model, Hydrol. Process., 25, 1212-1227, https://doi.org/10.1002/hyp.7886, 2011.

Kirchner, P. B., Bales, R. C., Molotch, N. P., Flanagan, J., and Guo, Q.: LiDAR measurement of seasonal snow accumulation along an elevation gradient in the southern Sierra Nevada, California, Hydrol. Earth Syst. Sci., 18, 4261-4275, https://doi.org/10.5194/hess-18-4261-2014, 2014.

Kunkel, K. E.: Simple procedures for extrapolation of humidity variables in the mountainous western United States, J. Climate, 2, 656-669, https://doi.org/10.1175/15200442(1989)002<0656:SPFEOH>2.0.CO;2, 1989.

Lapen, D. and Martz, L.: The measurement of two simple topographic indices of wind sheltering-exposure from raster digital elevation models Comput, Geosci., 19, 769-779, https://doi.org/10.1016/0098-3004(93)90049-B, 1993.

Lapo, K. E., Hinkelman, L. M., Raleigh, M. S., and Lundquist, J. D.: Impact of errors in the downwelling irradiances on simulations of snow water equivalent, snow surface temperature, and the snow energy balance, Water Resour. Res., 51, 1649-1670, https://doi.org/10.1002/2014WR016259, 2015.

Lehning, M., Löwe, H., Ryser, M., and Raderschall, N.: Inhomogeneous precipitation distribution and snow transport in steep terrain, Water Resour. Res., 44, W07404, https://doi.org/10.1029/2007WR006545, 2008.

Li, L. and Pomeroy, J. W.: Estimates of threshold wind speeds for snow transport using meteorological data, J. Appl. Meteorol., 36, 205-213, https://doi.org/10.1175/15200450(1997)036<0205:EOTWSF>2.0.CO;2, 1997.

Liston, G. E.: Representing subgrid snow cover heterogeneities in regional and global models, J. Climate, 17, 1381-1397, https://doi.org/10.1175/15200442(2004)017<1381:RSSCHI>2.0.CO;2, 2004.

Liston, G. E., and Elder, K.: A meteorological distribution system for high-resolution terrestrial modeling (MicroMet), J. Hydrometeorol., 7, 217-234, https://doi.org/10.1175/JHM486.1, 2006.

Liston, G. E., Haehnel, R. B., Sturm, M., Hiemstra, C. A., Berezovskaya, S., and Tabler, R. D.: Simulating complex snow distributions in windy environments using SnowTran-3D, J. Glaciol., 53, 241-256, https://doi.org/10.3189/172756507782202865, 2007.

Luijting, H., Vikhamar-Schuler, D., Aspelien, T., Bakketun, Å., and Homleid, M.: Forcing the SURFEX/Crocus snow model with combined hourly meteorological forecasts and gridded observations in southern Norway, The Cryosphere, 12, 2123-2145, https://doi.org/10.5194/tc-12-2123-2018, 2018.

Lundquist, J., Hughes, M., Gutmann, E., and Kapnick, S.: Our skill in modeling mountain rain and snow is bypassing the skill of our observational networks, B. Am. Meteorol. Soc., 100, 2473-2490, https://doi.org/10.1175/BAMS-D-19-0001.1, 2019.

Lv, Z. and Pomeroy, J. W.: Assimilating snow observations to snow interception process simulations, Hydrol. Proc., 34, 2229-2246, https://doi.org/10.1002/hyp.13720, 2020.

Macander, M. J., Swingley, C. S., Joly, K., and Raynolds, M. K.: Landsat-based snow persistence map for northwest Alaska, Remote Sens. Environ., 163, 23-31, https://doi.org/10.1016/j.rse.2015.02.028, 2015.

MacDonald, M. K., Pomeroy, J. W., and Pietroniro, A.: On the importance of sublimation to an alpine snow mass balance in the 
Canadian Rocky Mountains, Hydrol. Earth Syst. Sci., 14, 14011415, https://doi.org/10.5194/hess-14-1401-2010, 2010.

Mai, J., Kornelsen, K. C., Tolson, B. A., Fortin, V., Gasset, N., Bouhemhem, D., Schäfer, D., Leahy, M., Anctil, F., and Coulibaly, P.: The Canadian Surface Prediction Archive (CaSPAr): A Platform to Enhance Environmental Modeling in Canada and Globally, B. Am. Meteorol. Soc., 101, E341-E356, https://doi.org/10.1175/BAMS-D-19-0143.1, 2020 (data available at: https://caspar-data.ca/, last access: 29 January 2021).

Marks, D. and Dozier, J. Climate and energy exchange at the snow surface in the alpine region of the Sierra Nevada: 2. Snow cover energy balance, Water Resour. Res., 28, 3043-3054, https://doi.org/10.1029/92WR01483, 1992.

Marks, D., Domingo, J., Susong, D., Link, T., and Garen, D.: A spatially distributed energy balance snowmelt model for application in mountain basins, Hydrol. Process., 13, 1935-1959, https://doi.org/10.1002/(SICI)10991085(199909)13:12/13<1935::AID-HYP868>3.0.CO;2-C, 1999.

Marsh, C. and Vionnet, V.: Windmapper, GitHub, available at: https://github.com/Chrismarsh/Windmapper, last access: 29 January 2021.

Marsh, C. B., Pomeroy, J. W., and Spiteri, R. J.: Implications of mountain shading on calculating energy for snowmelt using unstructured triangular meshes, Hydrol. Process., 26, 1767-1778, https://doi.org/10.1002/hyp.9329, 2012.

Marsh, C. B., Spiteri, R. J., Pomeroy, J. W., and Wheater, H. S.: Multi-objective unstructured triangular mesh generation for use in hydrological and land surface models, Comput. Geosci., 119, 49-67, https://doi.org/10.1016/j.cageo.2018.06.009, 2018 (data available at https://github.com/Chrismarsh/mesher, last access: 29 January 2021).

Marsh, C. B., Pomeroy, J. W., Spiteri, R. J., and Wheater, H. S.: A finite volume blowing snow model for use with variable resolution meshes, Water Resour. Res., 56, e2019WR025307, https://doi.org/10.1029/2019WR025307, 2020a.

Marsh, C. B., Pomeroy, J. W., and Wheater, H. S.: The Canadian Hydrological Model (CHM) v1.0: a multi-scale, multi-extent, variable-complexity hydrological model - design and overview, Geosci. Model Dev., 13, 225-247, https://doi.org/10.5194/gmd13-225-2020, 2020b (data available at: https://github.com/ Chrismarsh/CHM, last access: 29 January 2021).

Marty, C., Philipona, R., Fröhlich, C., and Ohmura, A.: Altitude dependence of surface radiation fluxes and cloud forcing in the Alps: results from the alpine surface radiation budget network, Theor. Appl. Climatol., 72, 137-155, https://doi.org/10.1007/s007040200019, 2002.

Menke, R., Vasiljević, N., Mann, J., and Lundquist, J. K.: Characterization of flow recirculation zones at the Perdigão site using multi-lidar measurements, Atmos. Chem. Phys., 19, 2713-2723, https://doi.org/10.5194/acp-19-2713-2019, 2019.

Milbrandt, J. A., Bélair, S., Faucher, M., Vallée, M., Carrera, M. L., and Glazer, A.: The pan-Canadian high resolution $(2.5 \mathrm{~km}) \mathrm{de}-$ terministic prediction system, Weather Forecast., 31, 1791-1816, https://doi.org/10.1175/WAF-D-16-0035.1, 2016.

Morin, S., Horton, S., Techel, F., Bavay, M., Coléou, C., Fierz, C., Gobiet, A., Hagenmuller, P., Lafaysse, M., Lizar, M., Mitterer, C., Monti, F., Muller, K., Olefs, M., Snook, J. S., van Herwijnen, A., and Vionnet, V.: Application of physical snowpack models in support of operational avalanche hazard forecasting: A status report on current implementations and prospects for the future, Cold Reg. Sci. Technol., 170, 102910, https://doi.org/10.1016/j.coldregions.2019.102910, 2020.

Mott, R. and Lehning, M.: Meteorological modeling of very high-resolution wind fields and snow deposition for mountains, J. Hydrometeorol., 11, 934-949, https://doi.org/10.1175/2010JHM1216.1, 2010.

Mott, R., Schirmer, M., Bavay, M., Grünewald, T., and Lehning, M.: Understanding snow-transport processes shaping the mountain snow-cover, The Cryosphere, 4, 545-559, https://doi.org/10.5194/tc-4-545-2010, 2010.

Mott, R., Gromke, C., Grünewald, T., and Lehning, M.: Relative importance of advective heat transport and boundary layer decoupling in the melt dynamics of a patchy snow cover, Adv. Water Resour., 55, 88-97, https://doi.org/10.1016/j.advwatres.2012.03.001, 2013.

Mott, R., Vionnet, V., and Grünewald, T.: The seasonal snow cover dynamics: review on wind-driven coupling processes, Front. Earth Sci., 6, 197, https://doi.org/10.3389/feart.2018.00197, 2018.

Mott, R., Wolf, A., Kehl, M., Kunstmann, H., Warscher, M., and Grünewald, T.: Avalanches and micrometeorology driving mass and energy balance of the lowest perennial ice field of the Alps: a case study, The Cryosphere, 13, 1247-1265, https://doi.org/10.5194/tc-13-1247-2019, 2019.

Musselman, K. N., Pomeroy, J. W., Essery, R. L., and Leroux, N.: Impact of windflow calculations on simulations of alpine snow accumulation, redistribution and ablation, Hydrol. Process., 29, 3983-3999, https://doi.org/10.1002/hyp.10595, 2015.

Naaim-Bouvet, F., Bellot, H., and Naaim, M.: Back analysis of drifting-snow measurements over an instrumented mountainous site, Ann. Glaciol., 51, 207-217, https://doi.org/10.3189/172756410791386661, 2010.

Numri, P.: Recommendations on the verification of local weather forecasts, ECMWF, Shinfield Park, Reading, ECMWF Techincal Memoranda, No. 430, https://doi.org/10.21957/y1z1thg51, 2003.

Nuth, C. and Kääb, A.: Co-registration and bias corrections of satellite elevation data sets for quantifying glacier thickness change, The Cryosphere, 5, 271-290, https://doi.org/10.5194/tc-5-2712011, 2011.

Pelto, B. M., Menounos, B., and Marshall, S. J.: Multi-year evaluation of airborne geodetic surveys to estimate seasonal mass balance, Columbia and Rocky Mountains, Canada, The Cryosphere, 13, 1709-1727, https://doi.org/10.5194/tc-13-1709-2019, 2019.

Pfeffer, W. T., Arendt, A. A., Bliss, A. Bolch, T. Cogley J. G., Gardner, A. S., Hagen, J.-O., Hock, R., Kaser, G., Kienholz, C., Miles, E. S., Moholdt, G., Mölg, N., Paul, F., Radić, V., Rastner, P., Raup, B. H., Rich, J., Sharp, M. J., and The Randolph Consortium: The Randolph Glacier Inventory: A Globally Complete Inventory of Glaciers, J. Glaciol., 60, 537-52, https://doi.org/10.3189/2014JoG13J176, 2014.

Plüss, C. and Ohmura, A.: Longwave radiation on snowcovered mountainous surfaces, J. Appl. Meteorol., 36, 818-824, https://doi.org/10.1175/1520-0450-36.6.818, 1997

Pomeroy, J. W. and Gray, D. M.: Saltation of snow, Water Resour. Res., 26, 1583-1590, https://doi.org/10.1029/WR026i007p01583, 1990. 
Pomeroy, J. W. and Gray, D. M.: Snowcover Accumulation, Relocation and Management, National Hydrology Research Institute Science Report No. 7, Environment Canada, Saskatoon, 134 p., available at: https://www.usask.ca/hydrology-old/papers/ Pomeroy_Gray_1995.pdf (last access: 29 January 2021), 1995.

Pomeroy, J. W. and Male, D. H.: Steady-state suspension of snow, J. Hydrol., 136, 275-301, https://doi.org/10.1016/00221694(92)90015-N, 1992.

Pomeroy, J. W., Gray, D. M., and Landine, P. G.: The prairie blowing snow model: characteristics, validation, operation, J. Hydrol., 144, 165-192, https://doi.org/10.1016/0022-1694(93)90171-5, 1993.

Pomeroy, J. W., Gray, D. M., Shook, K. R., Toth, B., Essery, R. L. H., Pietroniro, A., and Hedstrom, N.: An evaluation of snow accumulation and ablation processes for land surface modelling, Hydrol. Process., 12, 2339-2367, https://doi.org/10.1002/(SICI)10991085(199812)12:15<2339::AID-HYP800>3.0.CO;2-L, 1998.

Pomeroy, J. W., Gray, D. M., Brown, T., Hedstrom, N. R., Quinton, W. L., Granger, R. J., and Carey, S. K.: The cold regions hydrological model: a platform for basing process representation and model structure on physical evidence, Hydrol. Process., 21, 2650-2667, https://doi.org/10.1002/hyp.6787, 2007.

Pomeroy, J. W., Fang, X., and Marks, D. G.: The cold rainon-snow event of June 2013 in the Canadian Rockiescharacteristics and diagnosis, Hydrol. Process., 30, 2899-2914, https://doi.org/10.1002/hyp.10905, 2016.

Pomeroy, J. W., Fang, X., and Ellis, C.: Sensitivity of snowmelt hydrology inMarmot Creek, Alberta, to forest cover disturbance, Hydrol. Process., 26, 1892-1905, https://doi.org/10.1002/hyp.9248, 2012.

Prein, A. F., Langhans, W., Fosser, G., Ferrone, A., Ban, N., Goergen, K., and Brisson, E.: A review on regional convection-permitting climate modeling: Demonstrations, prospects, and challenges, Rev. Geophys., 53, 323-361, https://doi.org/10.1002/2014RG000475, 2015.

Pritchard, D. M. W., Forsythe, N., O’Donnell, G., Fowler, H. J., and Rutter, N.: Multi-physics ensemble snow modelling in the western Himalaya, The Cryosphere, 14, 1225-1244, https://doi.org/10.5194/tc-14-1225-2020, 2020.

Pudasaini, S. P. and Hutter, K.: Avalanche dynamics: dynamics of rapid flows of dense granular avalanches, Springer Science and Business Media, 602 pp., https://doi.org/10.1007/978-3-54032687-8, 2007.

Revuelto, J., Lecourt, G., Lafaysse, M., Zin, I., Charrois, L., Vionnet, V., Dumont, M., Rabatel, A., Six, D., Condom, T., Morin, S., Viani, A., and Sirguey, P.: Multi-Criteria Evaluation of Snowpack Simulations in Complex Alpine Terrain Using Satellite and In Situ Observations, Remote Sensing, 10, 1171, https://doi.org/10.3390/rs10081171, 2018.

Quéno, L., Vionnet, V., Dombrowski-Etchevers, I., Lafaysse, M., Dumont, M., and Karbou, F.: Snowpack modelling in the Pyrenees driven by kilometric-resolution meteorological forecasts, The Cryosphere, 10, 1571-1589, https://doi.org/10.5194/tc-101571-2016, 2016.

Quéno, L., Karbou, F., Vionnet, V., and Dombrowski-Etchevers, I.: Satellite-derived products of solar and longwave irradiances used for snowpack modelling in mountainous terrain, Hydrol. Earth
Syst. Sci., 24, 2083-2104, https://doi.org/10.5194/hess-24-20832020, 2020.

Raderschall, N., Lehning, M., and Schär, C.: Finescale modeling of the boundary layer wind field over steep topography, Water Resour. Res., 44, W09425, https://doi.org/10.1029/2007WR006544, 2008.

Raleigh, M. S. and Small, E. E.: Snowpack density modeling is the primary source of uncertainty when mapping basinwide SWE with lidar, Geophys. Res. Lett., 44, 3700-3709, https://doi.org/10.1002/2016GL071999, 2017.

Rasouli, K., Pomeroy, J. W., Janowicz, J. R., Carey, S. K., and Williams, T. J.: Hydrological sensitivity of a northern mountain basin to climate change, Hydrol. Process., 28, 4191-4208, https://doi.org/10.1002/hyp.10244, 2014.

Rasmussen, R., Liu, C., Ikeda, K., Gochis, D., Yates, D., Chen, F., Tewari, M., Barlage, M., Dudhia, J., Yu, W., Miller, K., Arsenault, K., Grubisic, V, Thompson, G., and Gutmann, E.: High-resolution coupled climate runoff simulations of seasonal snowfall over Colorado: a process study of current and warmer climate, J. Climate, 24, 3015-3048, https://doi.org/10.1175/2010JCLI3985.1, 2011.

Réveillet, M., MacDonell, S., Gascoin, S., Kinnard, C., Lhermitte, S., and Schaffer, N.: Impact of forcing on sublimation simulations for a high mountain catchment in the semiarid Andes, The Cryosphere, 14, 147-163, https://doi.org/10.5194/tc14-147-2020, 2020.

Ryan, B.: A Mathematical Model for Diagnosis and Prediction of Surface Winds in Mountainous Terrain, J. Appl. Meteorol., 16, 571-584, https://doi.org/10.1175/15200450(1977)016<0571:AMMFDA>2.0.CO;2, 1977.

Rüschendorf, L.: The Wasserstein distance and approximation theorems, Prob. Theory Rel., 70, 117-129, https://doi.org/10.1007/BF00532240, 1985.

Sauter, T., Möller, M., Finkelnburg, R., Grabiec, M., Scherer, D., and Schneider, C.: Snowdrift modelling for the Vestfonna ice cap, north-eastern Svalbard, The Cryosphere, 7, 1287-1301, https://doi.org/10.5194/tc-7-1287-2013, 2013.

Sexstone, G. A., Clow, D. W., Fassnacht, S. R., Liston, G. E., Hiemstra, C. A., Knowles, J. F., and Penn, C. A.: Snow sublimation in mountain environments and its sensitivity to forest disturbance and climate warming, Water Resour. Res., 54, 1191-1211, https://doi.org/10.1002/2017WR021172, 2018.

Schirmer, M. and Pomeroy, J. W.: Processes governing snow ablation in alpine terrain - detailed measurements from the Canadian Rockies, Hydrol. Earth Syst. Sci., 24, 143-157, https://doi.org/10.5194/hess-24-143-2020, 2020.

Schlögl, S., Lehning, M., Fierz, C., and Mott, R.: Representation of horizontal transport processes in snowmelt modeling by applying a footprint approach, Front. Earth Sci., 6, 120, https://doi.org/10.3389/feart.2018.00120, 2018.

Schneiderbauer, S. and Prokop, A.: The atmospheric snowtransport model: SnowDrift3D, J. Glaciol., 57, 526-542, https://doi.org/10.3189/002214311796905677, 2011.

Shea, J. M., Marshall, S. J., and Livingston, J. M.: Glacier distributions and climate in the Canadian Rockies, Arct., Antarct., Alp. Res., 36, 272-279, https://doi.org/10.1657/15230430(2004)036[0272:GDACIT]2.0.CO;2, 2004.

Slater, A. G., Lawrence, D. M., and Koven, C. D.: Processlevel model evaluation: a snow and heat transfer metric, 
The Cryosphere, 11, 989-996, https://doi.org/10.5194/tc-11989-2017, 2017.

Smith, C. D.: Correcting the wind bias in snowfall measurements made with a Geonor T-200B precipitation gauge and alter wind shield, Proceedings of the 87th American Meteorology Society Annual Meeting, San Antonio, Texas, https://ams.confex.com/ ams/pdfpapers/118544.pdf (last access: 29 January 2021), 2007.

Sommer, C. G., Lehning, M., and Mott, R.: Snow in a very steep rock face: Accumulation and redistribution during and after a snowfall event, Front. Earth Sci., 3, 73, https://doi.org/10.3389/feart.2015.00073, 2015.

Vernay, M., Lafaysse, M., Mérindol, L., Giraud, G., and Morin, S.: Ensemble forecasting of snowpack conditions and avalanche hazard, Cold Reg. Sci. Technol., 120, 251-262, https://doi.org/10.1016/j.coldregions.2015.04.010, 2015.

Verseghy, D. L., McFarlane, N. A. and Lazare, M.: Class-A Canadian land surface scheme for GCMS, II. Vegetation model and coupled runs, Int. J. Climatol., 13, 347-370, https://doi.org/10.1002/joc.3370130402, 1993.

Vionnet, V.: Etudes du transport de la neige par le vent en conditions alpines: observations et simulation à l'aide d'un modèle couplé atmosphère/manteau neigeux, $\mathrm{PhD}$ thesis, Sciences et Techniques de l'Environnement, Université Paris-Est, France, 249 pp., available at: http://tel.archives-ouvertes.fr/tel-00781279 (last access: 29 January 2021), 2012.

Vionnet, V., Guyomarc'h, G., Bouvet, F. N., Martin, E., Durand, Y., Bellot, H., Bel C., and Puglièse, P.: Occurrence of blowing snow events at an alpine site over a 10 year period: observations and modelling, Adv. Water Resour., 55, 53-63, https://doi.org/10.1016/j.advwatres.2012.05.004, 2013.

Vionnet, V., Martin, E., Masson, V., Guyomarc'h, G., NaaimBouvet, F., Prokop, A., Durand, Y., and Lac, C.: Simulation of wind-induced snow transport and sublimation in alpine terrain using a fully coupled snowpack/atmosphere model, The Cryosphere, 8, 395-415, https://doi.org/10.5194/tc-8-395-2014, 2014.

Vionnet, V., Bélair, S., Girard, C., and Plante, A.: Wintertime subkilometer numerical forecasts of near-surface variables in the Canadian Rocky Mountains, Mon. Weather Rev., 143, 666-686, https://doi.org/10.1175/MWR-D-14-00128.1, 2015.

Vionnet, V., Dombrowski-Etchevers, I., Lafaysse, M., Quéno, L., Seity, Y., and Bazile, E.: Numerical weather forecasts at kilometer scale in the French Alps: evaluation and application for snowpack modeling, J. Hydrometeorol., 17, 2591-2614, https://doi.org/10.1175/JHM-D-15-0241.1, 2016.

Vionnet, V., Martin, E., Masson, V., Lac, C., Bouvet, F. N., and Guyomarc'h, G.: High-Resolution Large Eddy Simulation of Snow Accumulation in Alpine Terrain, J. Geophys. Res.-Atmos., 122, 11005-11021, https://doi.org/10.1002/2017JD026947, 2017.

Vionnet, V., Six, D., Auger, L., Dumont, M., Lafaysse, M., Quéno, L., Réveillet, M., Dombrowski-Etchevers, I., Thibert, E., and Vincent, C.: Sub-kilometer precipitation datasets for snowpack and glacier modeling in alpine terrain, Front. Earth Sci., 7, 182, https://doi.org/10.3389/feart.2019.00182, 2019.
Wagenbrenner, N. S., Forthofer, J. M., Lamb, B. K., Shannon, K. S., and Butler, B. W.: Downscaling surface wind predictions from numerical weather prediction models in complex terrain with WindNinja, Atmos. Chem. Phys., 16, 5229-5241, https://doi.org/10.5194/acp-16-5229-2016, 2016.

Wagenbrenner, N. S., Forthofer, J. M., Page, W. G., and Butler, B. W.: Development and Evaluation of a ReynoldsAveraged Navier-Stokes Solver in WindNinja for Operational Wildland Fire Applications, Atmosphere, 10, 672, https://doi.org/10.3390/atmos10110672, 2019.

Walmsley, J. L., Salmon, J. R., and Taylor, P. A.: On the application of a model of boundary-layer flow over low hills to real terrain, Bound.-Lay. Meteorol., 23, 17-46, https://doi.org/10.1007/BF00116110, 1982.

Warscher, M., Strasser, U., Kraller, G., Marke, T., Franz, H., and Kunstmann, H.: Performance of complex snow cover descriptions in a distributed hydrological model system: A case study for the high Alpine terrain of the Berchtesgaden Alps, Water Resour. Res., 49, 2619-2637, https://doi.org/10.1002/wrcr.20219, 2013.

Wayand, N. E., Marsh, C. B., Shea, J. M., and Pomeroy, J. W.: Globally scalable alpine snow metrics, Remote Sens. Environ., 213, 61-72, https://doi.org/10.1016/j.rse.2018.05.012, 2018.

Winstral, A. and Marks, D.: Simulating wind fields and snow redistribution using terrain-based parameters to model snow accumulation and melt over a semi-arid mountain catchment, Hydrol. Process., 16, 3585-3603, https://doi.org/10.1002/hyp.1238, 2002.

Winstral, A., Marks, D., and Gurney, R.: An efficient method for distributing wind speeds over heterogeneous terrain, Hydrol. Process., 23, 2526-2535, https://doi.org/10.1002/hyp.7141, 2009.

Winstral, A., Marks, D., and Gurney, R.: Simulating wind-affected snow accumulations at catchment to basin scales, Adv. Wat. Resour., 55, 64-79, https://doi.org/10.1016/j.advwatres.2012.08.011, 2013.

Winstral, A. and Marks, D.: Long-term snow distribution observations in a mountain catchment: Assessing variability, time stability, and the representativeness of an index sitem, Water Resour. Res., 50, 293-305, https://doi.org/10.1002/2012WR013038, 2014.

Winstral, A., Jonas, T., and Helbig, N.: Statistical downscaling of gridded wind speed data using local topography, J. Hydrometeorol., 18, 335-348, https://doi.org/10.1175/JHM-D-16-0054.1, 2017.

Wood, N.: The onset of separation in neutral, turbulent flow over hills, Bound.-Lay. Meteorol., 76, 137-164, https://doi.org/10.1007/BF00710894, 1995. 